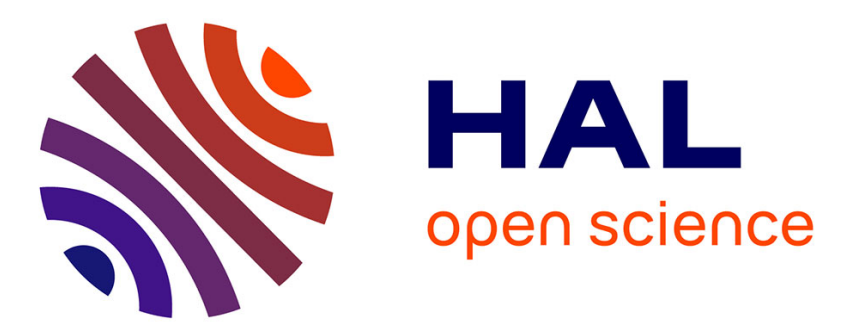

\title{
OPTICAL MODELING OF THE UPPER OCEAN IN RELATION TO ITS BIOGENOUS MATTER CONTENT (CASE-I WATERS)
}

\author{
A Morel
}

\section{- To cite this version:}

A Morel. OPTICAL MODELING OF THE UPPER OCEAN IN RELATION TO ITS BIOGENOUS MATTER CONTENT (CASE-I WATERS). Journal of Geophysical Research. Oceans, 1988, 93 (C9), pp.10749-10768. 10.1029/JC093iC09p10749 . hal-03277765

\section{HAL Id: hal-03277765 \\ https://hal.science/hal-03277765}

Submitted on 8 Jul 2021

HAL is a multi-disciplinary open access archive for the deposit and dissemination of scientific research documents, whether they are published or not. The documents may come from teaching and research institutions in France or abroad, or from public or private research centers.
L'archive ouverte pluridisciplinaire HAL, est destinée au dépôt et à la diffusion de documents scientifiques de niveau recherche, publiés ou non, émanant des établissements d'enseignement et de recherche français ou étrangers, des laboratoires publics ou privés. 


\title{
Optical Modeling of the Upper Ocean in Relation to Its Biogenous Matter Content (Case I Waters)
}

\begin{abstract}
ANDRÉ MOREL
Laboratoire de Physique et Chimie Marines, Université Pierre et Marie Curie, Villefranche-Sur-Mer, France

The aim of the present study is to review and tentatively to interpret the optical behavior of oceanic case I waters, those waters for which phytoplankton and their derivative play a predominant role in determining their optical properties. Chlorophyll-like pigment concentration is used as the index to quantify the algal material (living and detrital), and statistical relationships between this index and the depth of the euphotic layer, the spectral values of the attenuation coefficient for downwelling irradiance, or the scattering coefficient are investigated. On the basis of these statistical relationships a pigmentdependent optical model is developed. It allows the propagation of the visible radiant energy within the ocean or the backscattered radiation from the upper layer to be predicted as a function of the local phytoplanktonic content. Other geophysical or geochemical applications are derived which concern the heating rate due to penetrating visible radiations or the rate of energy storage due to photosynthesis. The nonlinear trends observed in the algal biomass-attenuation relationships are analyzed by (1) considering the rather regular change of the living-to-detrital organic carbon ratio which seems to occur in oceanic waters ranging from oligotrophic to eutrophic, and (2) accounting for the respective contributions of absorption (by pigmented cells) and of scattering (by all kind of particulates) in the attenuation process of radiant energy.
\end{abstract}

\section{INTRODUCTION}

During several decades, physicists have studied the optical properties of the ocean in a somewhat monodisciplinary way, a classical way when dealing with a new subject. The pioneer work effected by Jerlov [1951] during the Swedish deep-sea expedition (1947-1948) has evidenced the optical variability of the world ocean, and his paramount contribution has demonstrated that some order or regular trends exist in this natural varrability. This has resulted in the well-known Jerlov's optical classification: a classification which remains purely phenomenological in the sense that only the variations in the optical properties are quantified, whereas the causes of these variations are not identified and quantitatively assessed.

Meanwhile, biologists have sought for empirical relationships between easily measurable optical properties of a water body (e.g, Secchi disk depth) and its algal biomass content or for simple methods to describe the radiative ambiance in which the phytoplankton grow. The firm basis on which rests the definition of pertinent optical parameters was often lacking. The fundamental analyses given by Preisendorfer $[1961$, 1976] drastically clarified the confused panorama of the various optical parameters. By defining the inherent (absorption and scattering) properties and the apparent properties (which, in addition to being dependent on the inherent properties are dependent on the radiative field structure), Preisendorfer has laid the rational foundations for further work.

The Working Group 15, set up by the Scientific Committee on Oceanic Research (SCOR) in November 1963 under the chairmanship of J. E. Tyler, was the first oflicial opportunity of joining biologists and "opticists" with the aim of identifying "what measurement of irradiance is required by biological oceanographers...in relation to the determination of oceanic primary productivity [Tyler, 1966]." Under the auspices of this group, systematic simultaneous studies of the optical

\section{Copyright 1988 by the American Geophysical Union.}

Paper number $8 \mathrm{C} 0416$

0148-0227/88/008C-0416\$05.00 properties and of the algal content and activity of the ocean were undertaken, particularly during the SCOR Discoverer expedition in 1970 [SCOR, 1973]. It is worth noting that the first intensive study of the ocean reflectance (i.e., the "ocean color") was initiated during this expedition. In June 1972 a symposium was organized by N. G. Jerlov and E. Steemann Nielsen which resulted in a book entitled Optical Aspects of Oceanography [Austin, 1974]. The names of the organizers, as well as the content of this book, are proofs of the communication established at that time between physicists and biologists and of an effective cooperation, focused on the subject "light and primary production."

With the increasing data set acquired during several cruises in the 1970s (see the nonexhaustive lists in Table 1 and in Table 1 of Austin and Petzold [1985]) it has become obvious that the optical properties of the ocean waters are tightly subordinated to the abundance of pigmented algal cells. To acknowledge this fact, Smith and Baker [1978] coined the vocable "bio-optical state of ocean water." It was also recognized that in many situations, phytoplankton and their derivative, detrital products (mainly particulate, but also dissolved) play a predominant role in determining the optical properties of oceanic waters. These waters were classified as "case I" waters [Morel and Prieur, 1977] and opposed to "case II" waters for which sediments, or dissolved yellow substance, make an important or dominant contribution to the optical properties. Oceanic waters, as a rule, form the case I waters. In the absence of terrigenous influx (along arid coasts) and of resuspended sediment from the shelf, coastal waters can also, and often do, belong to case I. More than $98 \%$ of the world ocean waters, ranging from oligotrophic to locally eutrophic waters, are presumably of this category. This emphasizes the interest in reviewing and the need for understanding the nature of the links between the optical properties of case I waters and their biogenic content. It is the aim of the present work.

On the basis of the statistical analysis of a considerable amount of spectral data now available, a model is proposed which allows the optical properties and the solar radiation 
TABLE 1. Relevant Information Concerning the Cruises and the Optical-Biological Data Used in the Present Study

\begin{tabular}{|c|c|c|c|c|c|c|c|c|c|}
\hline $\begin{array}{l}\text { Date of } \\
\text { Cruise }\end{array}$ & Cruise/Ship & $N^{*}$ & $Z_{e}$ & Chl & $\varepsilon$ & $K_{d}(\lambda)$ & $\mathrm{POC} t$ & Location & Reference \\
\hline 1969 & MEDIPROD 1/Charcot & 12 & $\mathbf{X}$ & $\mathbf{X}$ & $\mathbf{X}$ & & & western Mediterranean & {$[$ Minas, 1971] } \\
\hline 1970 & SCOR WG 15/Discoverer & 20 & $\mathrm{x}$ & $\mathrm{x}$ & $\mathbf{X}$ & $\mathrm{x}$ & & $\begin{array}{l}\text { Sargasso Sea, Gulf of Mexico } \\
\text { Tropical East Pacific }\end{array}$ & $\begin{array}{l}\text { [Scientific Committee on Oceanic } \\
\quad \text { Research, 1973] }\end{array}$ \\
\hline 1971 & CINECA $2 /$ Charcot & 9 & $\mathbf{X}$ & $\mathrm{X}$ & $\mathbf{X}$ & $\mathbf{X}$ & $\mathbf{X}$ & Mauritanian upwelling & [Groupe MEDIPROD, 1971] \\
\hline 1974 & CINECA 5/Charcot & 27 & $\mathbf{X}$ & $\mathbf{x}$ & $\mathbf{X}$ & $\mathbf{X}$ & $\mathbf{X}$ & Mauritanian upwelling & [Groupe MEDIPROD, 1976] \\
\hline 1976 & GUIDOM/Charcot & 10 & $\mathbf{X}$ & $\mathbf{x}$ & $\mathrm{X}$ & $\mathrm{X}$ & $\mathrm{X}$ & Guinea Dome & [Groupe MEDIPROD, 1977] \\
\hline 1977 & ANTIPROD/M. Dufresne & 16 & $\mathbf{X}$ & $\mathrm{X}$ & $\mathbf{X}$ & $\mathrm{X}$ & & South Indian Antarctic & [Groupe MEDIPROD, 1978] \\
\hline 1978 & CIPREA/Suroit & 25 & $\mathbf{x}$ & $\mathbf{x}$ & $\mathbf{x}$ & & $\mathrm{x}$ & $\begin{array}{l}\text { Gulf of Guinea Equatorial } \\
\text { Atlantic }\end{array}$ & [Groupe MEDIPROD, 1981] \\
\hline 1979 & $\begin{array}{l}\text { C-FOX } \ddagger / \text { Vector/ } \\
\text { Endeavour }\end{array}$ & 15 & $\mathbf{X}$ & $\mathrm{X}$ & & $\mathbf{X}$ & & $\begin{array}{l}\text { Vancouver Island, Juan de } \\
\text { Fuca Strait }\end{array}$ & \\
\hline 1981 & RCA/Charcot & 14 & $\mathbf{X}$ & $\mathbf{x}$ & & & & upwelling off Portugal & [Groupe MEDIPROD, 1983] \\
\hline $\begin{array}{l}1975 / \\
1977\end{array}$ & CUEA Joint 1 and 2 & 151 & $\mathrm{X}$ & $\mathrm{X}$ & & & & $\begin{array}{l}\text { Peruvian and Mauritanian } \\
\text { upwelling }\end{array}$ & $\begin{array}{l}\text { [Barber and Huntsman, 1975; } \\
\text { Barber et al., 1978] }\end{array}$ \\
\hline \multirow[t]{2}{*}{1986} & PACIPROD/Charcot & 21 & $\mathrm{X}$ & $\mathrm{X}$ & $\mathbf{X}$ & $\mathrm{X}$ & & $\begin{array}{l}\text { Peruvian upwelling and } \\
\text { Galapagos zone }\end{array}$ & [Groupe MEDIPROD, 1988] \\
\hline & & 320 & 320 & 320 & 215 & 205 & 409 & & \\
\hline
\end{tabular}

*Number of stations where the depth of the euphotic layer $Z_{e}$ and the pigment profile Chl were determined. The energy storage efficiency $\varepsilon$ is determined only for these stations where primary production measurements were effected. The spectral values of the diffuse attenuation coefficient $K_{d}(\lambda)$ were computed from measurements of spectral downwelling irradiance carried out during seven cruises.

$\dagger$ The particulate organic carbon and the chlorophyll concentrations were determined on the same samples during four cruises, leading to 409 pairs of data.

$\ddagger$ For the cruise C-FOX, data were extracted from an unpublished (internal) report.

propagation within the ocean to be predicted from the phytoplanktonic pigment content. Other consequences such as the spectral reflectance, the heating rate, or the primary production are also derived from the relationships existing between optics and algal biomass. In turn, once a validated model for case I waters has been developed, the optical properties (which can be remotely sensed) become a powerful tool, at the world ocean scale, in biological studies of the marine phytosphere, including the geophysical and geochemical impacts of algal photosynthesis. While satisfying the requirements for belonging to case I, some waters may exhibit special optical properties. Such "anomalous" case I waters have been encountered in different kinds of red tides or in cocolithophorid-dominated blooms, for instance. They are out of the scope of this investigation. The chlorophyll $a$ concentration (or the $\mathrm{Chl} a+$ pheophytin $a$ concentration) is routinely measured and often is the only available index which can be used to quantify the biogenic content. Therefore a realistic approach consists of relating the optical properties in case I waters to this single parameter, even if some drawbacks result from this deliberate choice.

\section{DATA AND Methods}

The optical and related biological data used in this study are schematically presented in Table 1 . They were acquired during several (French and American) cruises in different parts of the world ocean and encompass a wide variety of situations with respect to the depth of the euphotic zone $Z_{e}$, which ranged from 7 to $128 \mathrm{~m}$, and to the phytoplanktonic content, which varied within this zone from 3 to more than $300 \mathrm{mg}$ Chl $a \mathrm{~m}^{-2}$. According to a commonly accepted rule, $Z_{e}$ is defined as that depth at which the downwelling irradiance, expressed as photosynthetically available radiation (PAR), is reduced to $1 \%$ of its value at the surface. PAR is defined as the amount of photons, available at a particular depth, ideally within the spectral range $350-700 \mathrm{~nm}$ [see Tyler, 1966] and practically within the 400 - to $700-\mathrm{nm}$ range.

The optical measurements included the following:
1. The downwelling irradiance was measured at various depths either in terms of PAR (quanta $\mathrm{m}^{-2} \mathrm{~s}^{-1}$ ) by using quantum meters equipped with flat cosine collectors or in terms of spectral values of the downwelling irradiance $E_{d}(\lambda)$ (in $\mathrm{W} \mathrm{m}^{-2} \mathrm{~nm}^{-1}$ ) by using a spectroradiometer.

2. The total incoming radiation rate (spectral range 300$4000 \mathrm{~nm}$ ) was measured with calibrated (Eppley) pyranometers installated on the deck and recorded on all days.

3. The scattering coefficient $b_{550}$ (in $\mathrm{m}^{-1}$ ) at wavelength $\lambda=550 \mathrm{~nm}$ was measured in situ with a profiler instrument.

The biological and chemical measurements, relevant to the present study, included the following:

1. The particulate organic carbon concentration was determined after filtration on precombusted GFC Whatman filters; the total (dry) seston was occasionally measured on the same preweighted filters before carbon, hydrogen, and nitrogen analysis.

2. The pigment ( $\mathrm{Chl} a+$ Pheo $a$ ) concentration either was determined from measurements on filtered samples taken at discrete selected depths or was derived from continuous calibrated fluorescence profiles (no extraction).

3. The primary production at selected depths within the euphotic layer was measured in situ by using the ${ }^{14} \mathrm{C}$ method.

The methods used for these optical, chemical, and biological measurements are described in details in the cruise reports (see Table 1).

For the present study the above data were processed and arranged as follows:

1. The depth of the euphotic layer $Z_{e}$ was computed by a logarithmic interpolation made on the vertical $\operatorname{PAR}(Z)$ profile.

2. The spectral values of the attenuation coefficient for downwelling irradiance $K_{d}(\lambda)$ were derived from the spectral values of downwelling irradiances as measured just above the surface, $E_{d, 0}(\lambda)$, and at a depth $Z$ close to $Z_{e}, E_{d, z}(\lambda) ; K_{d}(\lambda)$ was then computed according to

$$
K_{d}(\lambda)=Z^{-1} \ln \left[E_{d, 0}(\lambda) / E_{d, z}(\lambda)\right]
$$

(the subscript $d$ will be hereinafter omitted when no confusion may occur). With the aim of increasing the $K(\lambda)$ data body, 


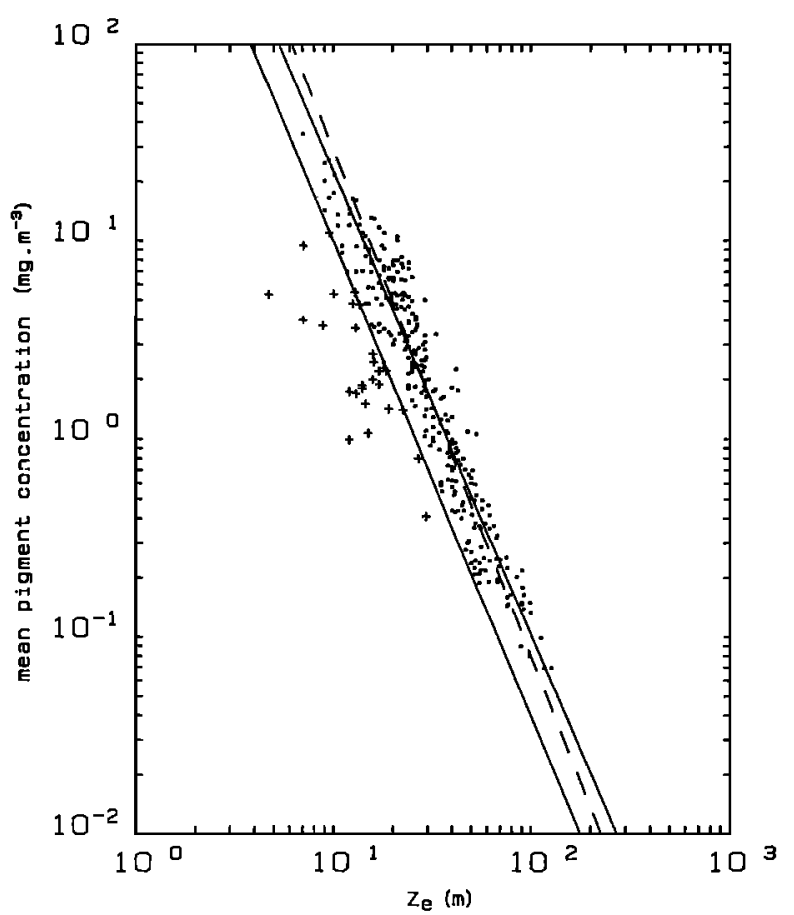

Fig. 1. Mean pigment concentration $C$ within the euphotic layer versus the depth of this layer, $Z_{e}$, for all (320) stations listed in Table 1. The dots are for case I waters and the pluses are for turbid case II waters, excluded from the regression analysis by the line corresponding to $y=-2.40 x+3.40$ (with $y=\log _{10} C$ and $x=\log _{10} Z_{e}$ ); the two other straight (solid and dashed) lines correspond to the regression of $y$ versus $x$ and $x$ versus $y$.

particularly in the "red" part of the spectrum where $E_{d, z}(\lambda)$ often becomes undetectable when $Z$ approaches $Z_{e}$, additional $K(\lambda)$ spectra were computed by considering an upper layer with a reduced thickness of the order of $Z_{e} / 2$ or $Z_{e} / 3$ (all the $K(\lambda)$ spectra used in the present study are shown on Figure $5 a)$.

3. The daily total irradiation $E_{\mathrm{TOT}}$ (in $\mathrm{J} \mathrm{m}^{-2} \mathrm{~d}^{-1}$ ) was obtained by integrating the continuous records. From $E_{\text {Tor }}$ the daily photosynthetic radiation $(400-700 \mathrm{~nm})$ PAR was obtained as [Jitts et al., 1976] PAR $=0.43 E_{\mathrm{TOT}}$ (in $\mathrm{J} \mathrm{m}^{-2} \mathrm{~d}^{-1}$ ) or PAR $=1.19 \times 10^{18} E_{\text {TOT }}$ (in quanta $\mathrm{m}^{-2} \mathrm{~d}^{-1}$ ).

4. When converted into its energetic equivalent, the daily primary production within the entire euphotic zone ( $\mathrm{g}$ C fixed $\mathrm{m}^{-2} \mathrm{~d}^{-1}$ ) allows the photosynthetically stored radiation (PSR) to be computed [Morel, 1978]; the conversion was made on the basis of $39 \mathrm{~kJ} / \mathrm{g}$ of carbon fixed. Then PSR was compared to the daily amount of radiant energy at the surface PAR. A dimensionless number $\varepsilon$ can be obtained as

$$
\varepsilon=\text { PSR/PAR }
$$

which describes the photosynthetic efficiency of algae in storing energy within the entire euphotic column [Morel, 1978].

5. The pigment's ( $\mathrm{Chl} a+$ Pheo $a$ ) concentrations (discrete values, or profiles) were used to compute a "mean" pigment concentration $C\left(\mathrm{mg} \mathrm{m}^{-3}\right)$ within the layer considered (euphotic or thinner) regardless of the vertical pigment distribution. The product $Z_{\mathrm{e}} C$ provides the areal concentration $C_{\text {TOт }}$ (in $\mathrm{mg}(\mathrm{Chl} a+$ Pheo $\left.a) \mathrm{m}^{-2}\right)$.

\section{RESULTS}

\section{Euphotic Depth and Mean Pigment}

\section{Concentration Relationship}

A statistical study showed that the most significant correlation between $Z_{e}$ and $C$ was found when a linear regression analysis was performed on the log-transformed data. The turbid case II waters, always encountered near the coast, were excluded from the regression analysis (the euphotic depth in that case is reduced and not correlated with $C$ ). In addition to the visual observation combined with the knowledge of the geographical position of the station the "anomalously" high scattering coefficient forms the numerical criterion which allows water to be classified as turbid case II waters [Morel and Prieur, 1977; Gordon and Morel, 1983, Figure 5a]. The location of these rejected stations in the log-log plot of Figure 1 suggests that a straight line can be used to separate these turbid case II waters from case I waters. The equation describing this line $\left(\log _{10} Z=-2.40 \log _{10} C+3.40\right)$ has also been used as an exclusion test when dealing with the American data for which no scattering measurements were available (in effect, very few stations in the Peruvian zone were identified as "turbid"). Some "yellow substance dominated" case II waters were also rejected $f$ om the regression analysis by the same test; the corresponcing waters (in British Columbia inlets) were already identified as such according to the high absorption coefficient measured on filtered samples in the shortwavelength domain $(\lambda<500 \mathrm{~nm})$.

For case I waters only a highly significant $\left(r^{2}=0.914\right)$ relationship does exist between the log-transformed data (Figure 1). The depth (in meters) of and the mean pigment concentration (in milligrams per cubic meter) within the euphotic layer are thus related through

$$
Z_{e}=38.0 C^{-0.428}
$$

or

$$
C=4910 Z_{e}^{-2.34}
$$

Equation (2) can be transformed into

$$
C_{\text {Tot }}=4910 Z_{e}^{-1.34}
$$

which makes explicit the relationship between the total pigment content integrated through the photic zone (in milligrams per square meter) and its thickness $Z_{e}$.

The major discrepancy (see Figure 2) between this result and the result previously published by Lorenzen [1972] originates from the fact that the $1 \%$ level, in Lorenzen's study, was determined by using a Weston photovoltaic selenium cell. Owing to the spectral response of such a detector (with a sensitivity maximum in the 500 - to $600-\mathrm{nm}$ band) the $1 \%$ level which is measured is for green-yellow light. It roughly coincides with the 1\% PAR level in "green" productive waters $\left(C>1 \mathrm{mg} \mathrm{m}^{-3}\right.$ ) for which the absorption minimum lies around $560 \mathrm{~nm}$ (see, e.g., Figure 8 of Morel and Prieur [1977]). In blue mesotrophic or oligotrophic waters, however, the $1 \%$ green light level is obviously less deep than the 1\% PAR level, as the remnant light is predominantly blue. Thus the divergence between the Lorenzen's curve and the present one increases with increasing $Z_{e}$.

\section{Attenuation Coefficient for Downwelling PAR and the Pigment Concentration}

The attenuation coefficient $K_{\mathrm{PAR}}$ concerns the whole photosynthetic spectrum involved in the definition of PAR (i.e., 400 $700 \mathrm{~nm})$. From the definition of $Z_{e}(1 \%$ PAR level) it becomes

$$
K_{\mathrm{PAR}} Z_{e}=4.605(=-\ln 0.01)
$$

Equation (4) combined with (1) leads to

$$
\bar{K}_{\mathrm{PAR}}\left(0, Z_{e}\right)=0.121 C^{0.428}
$$




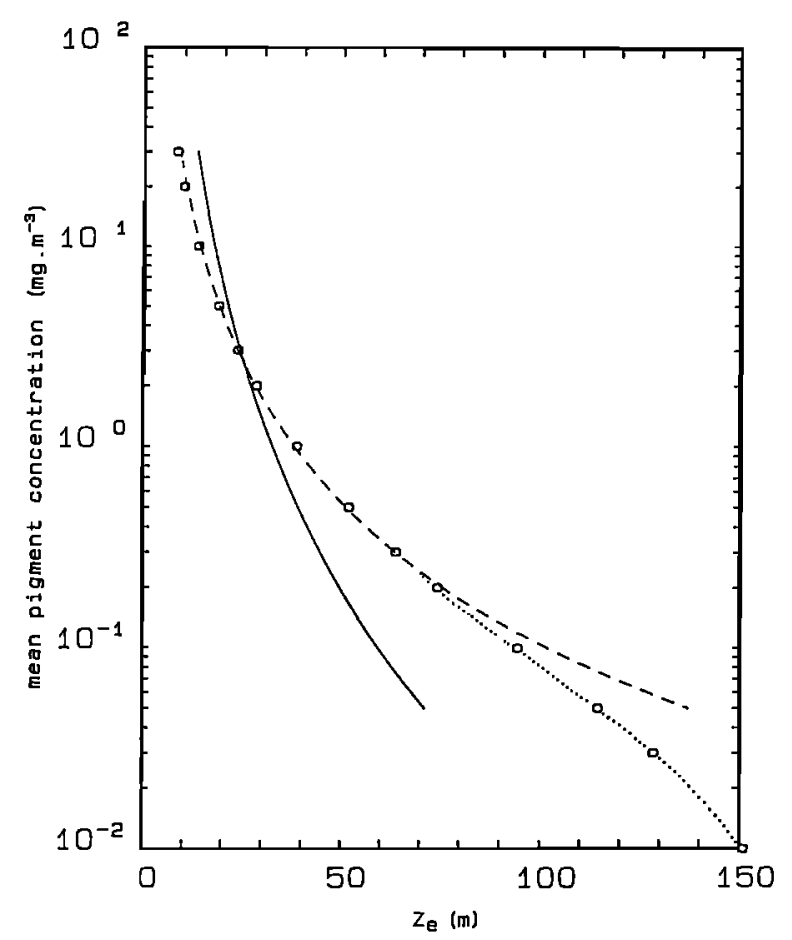

Fig. 2. Mean pigment concentration $C$ within the euphotic layer versus the depth of this layer $Z_{e}$ (linear scale); dashed curve according to equation (2) and solid curve according to $Z_{e}=32.51 C^{-0262} \mathrm{de}-$ duced from Lorenzen [1972]. The circles linked by a dotted curve correspond to the products of a model which makes use of the spectral attenuation coefficients (see text and equation (11)).

where the overbar denotes that the attenuation coeflicient is a mean coefficient valid for the whole euphotic layer from 0 to $Z_{e}$

As for case I waters the optical properties were exclusively governed by their biogenous content (the algal cells and their immediate derivatives), $\bar{K}_{\mathrm{PAR}}$ is well correlated to the algal

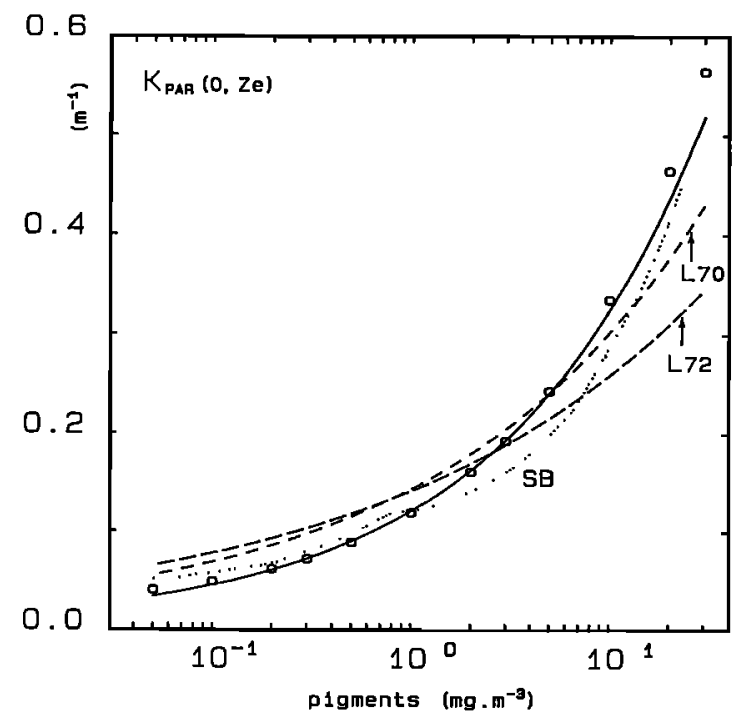

Fig. 3a. Attenuation coefficient for downwelling photosynthetic available radiation, $\bar{K}_{\mathrm{PAR}}$, as a function of the mean pigment concentration within the euphotic layer; solid curve according to (5), curves labeled SB from Smith and Baker [1978] and L70 and L72 derived from the data of Lorenzen [1970, 1972]. The circles correspond to the products of the spectral model (see text and equations (11) and (4)).

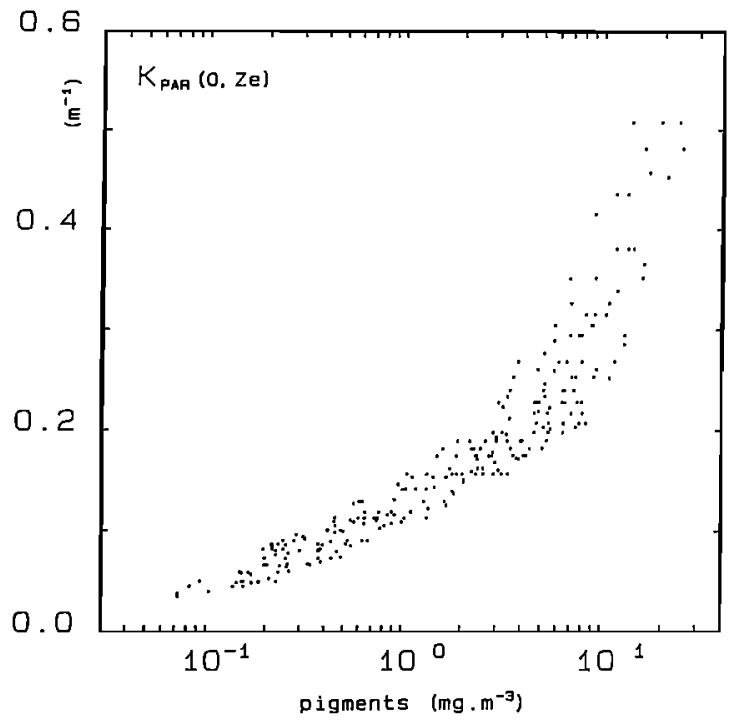

Fig. $3 b . \bar{K}_{\mathrm{PAR}}\left(0, Z_{e}\right)$ data as a function of the mean pigment concentration computed for the entire euphotic zone (case I waters only).

index $C$. The relationship, however, is not a simple linear one, and the curve corresponding to (5) is shown on Figure $3 a$. The $K_{\mathrm{PAR}}\left(0, Z_{e}\right)$ data are plotted versus the actual mean pigment concentration on Figure $3 b$.

This "nonlinear biological effect" [Smith and Baker, 1978] has been evidenced a long time ago, even if not well quantified because of limitations in optical instrumentation (Secchi disk in the study by Riley [1956] or Se cell in the study by Lorenzen [1972]). Examining PAR measurements, as here, Smith and Baker [1978] chose to describe the global nonlinear trend as being the result of the juxtaposition of two domains $\left(C<0.8\right.$ and $C>0.8 \mathrm{mg}(\mathrm{Chl} a+$ Pheo $\left.a) \mathrm{m}^{-3}\right)$ inside which linearity should exist with differing slopes. The results shown on Figure $3 a$ do not suggest that such a discontinuity at $C$ around $1 \mathrm{mg} \mathrm{m}^{-3}$ actually exists, and it is believed that a continuous variation of $\bar{K}_{\mathrm{PAR}}$ with $C$, as expressed by the power law (5), is appropriate and physically more realistic. The somewhat mysterious value of the exponent, about 0.4 , however, remains to be explained.

It is not useless to recall the similar approaches or explanation, attempted by Lorenzen [1972] and by Smith and Baker [1978], which consist of splitting $K_{\mathrm{PAR}}$ into three components according to

$$
K_{\mathrm{PAR}}=K_{w}+k_{c} C+K_{x}
$$

where $K_{w}$ is the partial coefficient due to the water itself, assumed to be a constant, $k_{c}$ is the chlorophyll-specific attenuation coefficient due to algae, $C$ is the Chl $a$ (or Chl $a+$ Pheo $a$ in the Smith-Baker study) concentration, and finally, $K_{x}$ represents the contribution to diffuse attenuation by other noncovarying detritic substances (particulate and dissolved). The approximation made when setting this equation (and using Beer's law when writing $k_{c} C$ ) is to consider $K$ as an inherent property and therefrom to use the additivity principle which allows $K_{\mathrm{PAR}}$ to be split into partial components. The validity of such an approximation is not discussed at this step. The basic idea behind the above decomposition is to explain the nonlinear variation of $K_{\mathrm{PAR}}$ with respect to $C$ by invoking the influence of the additional term $K_{x}$, whereas the term directly related to algae would be a linear function of $C$ 


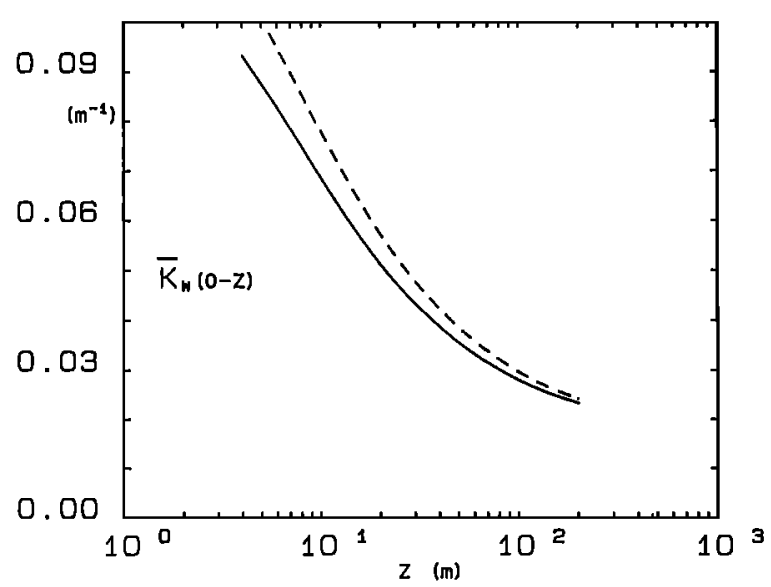

Fig. 4. Attenuation coefficient for downwelling photosynthetic radiation (PAR) in ideally pure water. This coefficient $\bar{K}_{w}$, spectrally $(400-700 \mathrm{~nm})$ averaged, varies with the thickness of the layer under consideration, denoted $(0-Z)$, with $Z$ varying from a few meters to 200 $\mathrm{m}$; the solid curve represents $\bar{K}_{w}$ when PAR is expressed as energy (W $\mathrm{m}^{-2}$ ) and the dashed curve represents $\tilde{K}_{w}$ when PAR is expressed as quanta $\mathrm{m}^{-2} \mathrm{~s}^{-1}$.

through the constant coeflicient $k_{c}$ (or even two successive coefficients in the Smith and Baker study).

After having assigned a constant value to $K_{w}\left(0.0384 \mathrm{~m}^{-1}\right.$ or $0.027 \mathrm{~m}^{-1}$, in the Lorenzen or Smith-Baker study, respectively) and another constant value to $k_{c}\left(0.0138 \mathrm{~m}^{2} \mathrm{mg}^{-1} \mathrm{Chl}\right.$ $a$, in the Lorenzen study) or two successive values $(0.091$ and $0.016 \mathrm{~m}^{2} \mathrm{mg}^{-1} \mathrm{Chl} a$ when $C<0.8$ and $C>0.8 \mathrm{mg} \mathrm{m}^{-3}$, respectively, in the Smith-Baker study) this method is expected to provide a quantitative evaluation of the respective roles played by living organisms, detrital material, and water in the PAR attenuation process. Such an explanation comes up against several difficulties apparently ignored in the studies mentioned. These difficulties originate from the polychromatic nature of the radiation involved in the definition of PAR and hence of $K_{\mathrm{PAR}}$.

1. $K_{w}$ is a value averaged over the whole spectrum. It is computed for a layer extending from zero to a certain depth $Z$ within an ideally optically pure ocean. When computing this depth-averaged value, denoted $\bar{K}_{W}(0, Z)$, the spectral distribution of the light at the surface, $E_{0}(\lambda)$, and at the depth $Z$, $E_{z}(\lambda)$, intervenes according to

$$
\begin{array}{r}
\bar{K}_{w}(0, Z)=-Z^{-1} \log \left\{\int_{400}^{700} E_{0}(\lambda) \exp \left[-K_{w}(\lambda) Z\right] d \lambda\right\} \\
\\
\left.\int_{400}^{700} E_{0}(\lambda) d \lambda\right\}
\end{array}
$$

In other words, $\bar{K}_{w}(0, Z)$ is no longer a constant as soon as it is computed for a layer of variable thickness. When $Z$ increases, the remnant light tends to become monochromatic, with the irradiance maximum centered on the minimum of $K_{w}$, and the averaged value $\bar{K}_{w}(0, Z)$ decreases accordingly (see Figure 4; $E_{0}(\lambda)$ is taken from Figure 8).

2. The constant coefficient $k_{c}$ is also a doubly averaged value, over the spectrum and over the layer considered. The result of such averaging depends on the spectral composition of the underwater light and on its change with depth. Since the phytoplankton concentration depicted by $C$ governs both the thickness $Z_{e}$ and the spectral quality of the penetrating radiations, $k_{c}$ depends on $C$. This effect was discussed in detail by Morel [1978] and by Atlas and Bannister [1980]; although these discussions dealt with the absorption coefficient, they, however, remain essentially unchanged regarding $\boldsymbol{k}_{c}$.

3. In the presence of algae the $\bar{K}_{w}(0, Z)$ values previously obtained through (4) are no longer valid since the spectral change in submarine irradiance due to algal absorption reacts to the way of averaging $\bar{K}_{w}(\lambda)$ over the spectrum.

In other words, an expression like (6) which is supposed to solve a problem by a simple way conceals other much more complicated problems. These drawbacks, however, can be circumvented if the question is analytically examined in terms of spectral values $K(\lambda)$. Unless this is done, there is no effective possibility of explaining the value of the exponent (0.428) which appears in the $\bar{K}_{\mathrm{PAR}^{-}}-C$ relationship.

\section{Spectral Values of Attenuation Coefficient $K(\lambda)$ and Mean Pigment Concentration}

The principal task consists of studying the quantity $K(\lambda)$ $-K_{w}(\lambda)$ along with $C$, the mean pigment concentration within the layer under consideration (the euphotic layer or less). $K_{w}(\lambda)$ represents the spectral values of the diffuse attenuation coefficient for pure oceanic waters. $K_{w}(\lambda)$ is well approximated by its lower limiting value which is expressed as

$$
K_{w}(\lambda)=a_{w}(\lambda)+\frac{1}{2} b_{w}(\lambda)
$$

where $a_{w}$ and $b_{w}$ stand for the absorption and the molecular scattering coefficients, respectively, for optically pure seawater. The validity of the above formulation which, in effect, represents a lower limit was discussed in detail by Smith and Baker [1981]. The $K_{w}(\lambda)$ values used in the present study (Table 2) differ very slightly from those proposed by Smith and Baker [1981], mainly in the vicinity of $500 \mathrm{~nm}$.

The data body retained for statistical analyses consists of $176 K(\lambda)$ spectra (Figure $5 a$ ) which are reasonably well ordered with respect to the corresponding pigment concentration, with all $K(\lambda)$ values increasing with increasing $C$. The spectra obtained at stations definitely identified as belonging to turbid or yellow substance dominated case II waters were excluded (these stations are those excluded in Figure 1). A careful inspection reveals, however, that in the blue domain, two patterns exist among the retained spectra; one is characterized by a maximum occurring between about 420 and $440 \mathrm{~nm}$, the other is characterized by a regular ascending slope toward $400 \mathrm{~nm}$. It is clear that the latter pattern demonstrates a significative influence of yellow substance or other colored organic detritus, even if these waters were kept as in case I. It is also clear that some noise (or disorder) appears beyond $650 \mathrm{~nm}$ mainly due to instrumental limitations.

The statistical analysis was performed (as before for $Z_{e}$ ) on the log-transformed data at each wavelength (every $5 \mathrm{~nm}$ ) in the 400- to 700-nm domain. Such a transforming allows significant linear relationships between $\log \left[K(\lambda)-K_{w}(\lambda)\right]$ and $\log [C]$ to be obtained by regression (Figure $7 a$ ). From these relationships the $K(\lambda)$ coefficients can be expressed as functions of $C$ under the general power law form

$$
K(\lambda)=K_{w}(\lambda)+\chi_{c}(\lambda) C^{e(\lambda)}
$$

which includes a coefficient $\chi_{c}$ and an exponent $e$, both functions of $\lambda$. In this analysis the number of available $K(\lambda)$ values changes, depending on the wavelength considered (Figure 6). 
TABLE 2. Values Used for $(K w)$, and Values Resulting From $(\chi(\lambda)$ and $e(\lambda))$, Statistical Analyses of the Attenuation Coefficient for Downward Irradiance

\begin{tabular}{|c|c|c|c|}
\hline $\begin{array}{c}\text { Wavelength, } \\
\text { nm }\end{array}$ & $\underset{\mathbf{m}^{-1}}{K_{w}(\lambda)}$ & $x(\lambda)$ & $e(\lambda)$ \\
\hline 400 & 0.0209 & 0.1100 & 0.668 \\
\hline 405 & 0.0200 & 0.1110 & 0.672 \\
\hline 410 & 0.0196 & 0.1125 & 0.680 \\
\hline 415 & 0.0189 & 0.1135 & 0.687 \\
\hline 420 & 0.0183 & 0.1126 & 0.693 \\
\hline 425 & 0.0182 & 0.1104 & 0.701 \\
\hline 430 & 0.0171 & 0.1078 & 0.707 \\
\hline 435 & 0.0170 & 0.1065 & 0.708 \\
\hline 440 & 0.0168 & 0.1041 & 0.707 \\
\hline 445 & 0.0166 & 0.0996 & 0.704 \\
\hline 450 & 0.0168 & 0.0971 & 0.701 \\
\hline 455 & 0.0170 & 0.0939 & 0.699 \\
\hline 460 & 0.0173 & 0.0896 & 0.700 \\
\hline 465 & 0.0174 & 0.0859 & 0.703 \\
\hline 470 & 0.0175 & 0.0823 & 0.703 \\
\hline 475 & 0.0184 & 0.0788 & 0.703 \\
\hline 480 & 0.0194 & 0.0746 & 0.703 \\
\hline 485 & 0.0203 & 0.0726 & 0.704 \\
\hline 490 & 0.0217 & 0.0690 & 0.702 \\
\hline 495 & 0.0240 & 0.0660 & 0.700 \\
\hline 500 & 0.0271 & 0.0636 & 0.700 \\
\hline 505 & 0.0320 & 0.0600 & 0.695 \\
\hline 510 & 0.0384 & 0.0578 & 0.690 \\
\hline 515 & 0.0445 & 0.0540 & 0.685 \\
\hline 520 & 0.0490 & 0.0498 & 0.680 \\
\hline 525 & 0.0505 & 0.0475 & 0.675 \\
\hline 530 & 0.0518 & 0.0467 & 0.670 \\
\hline 535 & 0.0543 & 0.0450 & 0.665 \\
\hline 540 & 0.0568 & 0.0440 & 0.660 \\
\hline 545 & 0.0615 & 0.0426 & 0.655 \\
\hline 550 & 0.0640 & 0.0410 & 0.650 \\
\hline 555 & 0.0683 & 0.0400 & 0.645 \\
\hline 560 & 0.0717 & 0.0390 & 0.640 \\
\hline 565 & 0.0762 & 0.0375 & 0.630 \\
\hline 570 & 0.0807 & 0.0360 & 0.623 \\
\hline 575 & 0.0940 & 0.0340 & 0.615 \\
\hline 580 & 0.1070 & 0.0330 & 0.610 \\
\hline 585 & 0.1280 & 0.0328 & 0.614 \\
\hline 590 & 0.1570 & 0.0325 & 0.618 \\
\hline 595 & 0.2000 & 0.0330 & 0.622 \\
\hline 600 & 0.2530 & 0.0340 & 0.626 \\
\hline 605 & 0.2790 & 0.0350 & 0.630 \\
\hline 610 & 0.2960 & 0.0360 & 0.634 \\
\hline 615 & 0.3030 & 0.0375 & 0.638 \\
\hline 620 & 0.3100 & 0.0385 & 0.642 \\
\hline 625 & 0.3150 & 0.0400 & 0.647 \\
\hline 630 & 0.3200 & 0.0420 & 0.653 \\
\hline 635 & 0.3250 & 0.0430 & 0.658 \\
\hline 640 & 0.3300 & 0.0440 & 0.663 \\
\hline 645 & 0.3400 & 0.0445 & 0.667 \\
\hline 650 & 0.3500 & 0.0450 & 0.672 \\
\hline 655 & 0.3700 & 0.0460 & 0.677 \\
\hline 660 & 0.4050 & 0.0475 & 0.682 \\
\hline 665 & 0.4180 & 0.0490 & 0.687 \\
\hline 670 & 0.4300 & 0.0515 & 0.695 \\
\hline 675 & 0.4400 & 0.0520 & 0.697 \\
\hline 680 & 0.4500 & 0.0505 & 0.693 \\
\hline 685 & 0.4700 & 0.0440 & 0.665 \\
\hline 690 & 0.5000 & 0.0390 & 0.640 \\
\hline 695 & 0.5500 & 0.0340 & 0.620 \\
\hline 700 & 0.6500 & 0.0300 & 0.600 \\
\hline
\end{tabular}

It drops from more than 170 (in the 420 - to $550-\mathrm{nm}$ domain) to an uncomfortably low figure at the red end of the spectrum. The correlation coefficient follows approximately the same trend (Figure 6), with $r^{2}$ values higher than 0.90 in the 420 - to $530-\mathrm{nm}$ band, a drop around $600 \mathrm{hm}$ (due to the steep slope of

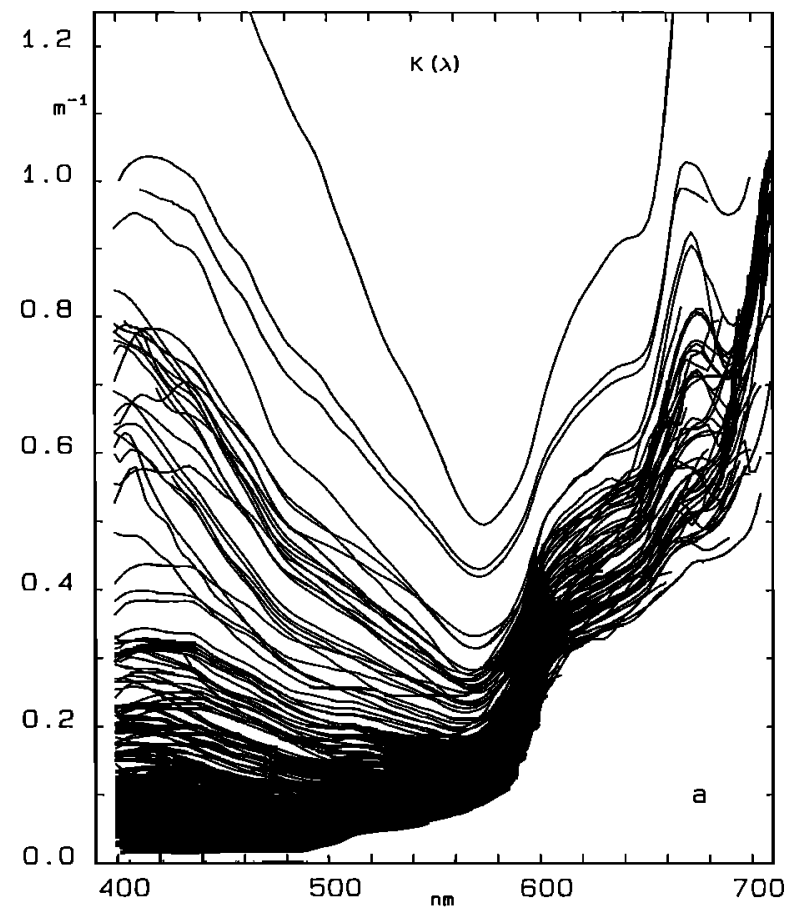

Fig. 5a. Experimental values of the attenuation coefficient for downwelling irradiance $K(\lambda)$ as a function of the wavelength (case $I$ waters only, see text). These spectra (176) form the data bank used in the statistical analysis.

the water absorption), a relative restoration to acceptable levels in the 610- to $650-\mathrm{nm}$ domain, and finally a deteriorated situation in the far-red region.

When considering the data bank, two kinds of bias must be acknowledged: (1) the oligotrophic waters (low $C$ ) are virtually absent in the statistical treatment when dealing with the long

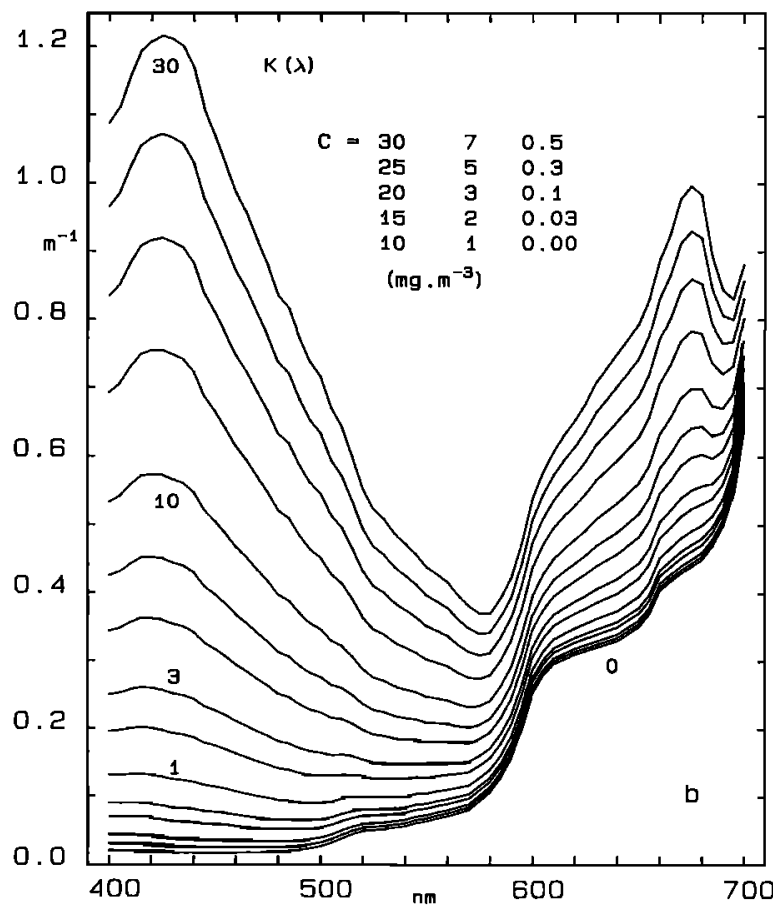

Fig. 5b. Modeled values of $K(\lambda)$ in case I waters with increasing pigment concentrations as given in the inset. These spectra are produced by using equation (9) and the values listed in Table 2. 


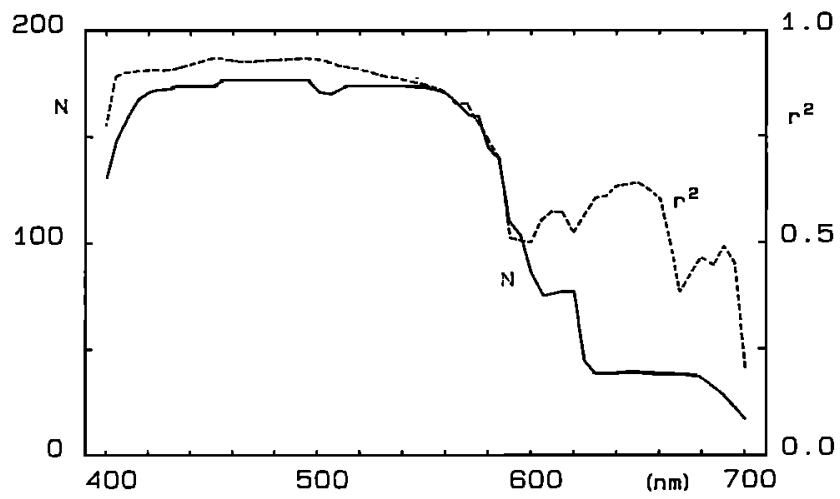

Fig. 6. As a function of the wavelength, $N$, the number of $K(\lambda)$ values used in the regression analysis, and $r^{2}$, the coefficient of determination, which appeared when fitting equations as in (9), are plotted. Note that the drop in $N$ beyond $600 \mathrm{~nm}$ results not only from a reduced number of available data (see Figure $5 a$ ) but also from having excluded data with $C<2$ or $3 \mathrm{mg} \mathrm{m}^{-3}$ which often appeared unreliable and which strongly depressed $r^{2}$.

wavelengths $(\lambda>650 \mathrm{~nm})$; therefore the $\chi_{c}$ and $e$ values beyond $650 \mathrm{~nm}$ are only extracted from the mesotrophic and eutrophic waters (moderate and high $C$ values), and (2) conversely, when dealing with the blue part of the spectrum, some eutrophic waters are eliminated in the statistical treatment when the yellow substance interference is identified. In spite of these eliminations the correlation coefficient in the 400 - to 420-nm domain is slightly lowered.

Figure $7 a$ shows, for example, the log-transformed data for $\lambda=450 \mathrm{~nm}$ with the straight lines corresponding to the regressions of $y$ versus $x$ or $x$ versus $y(x=\log C, y=\log [K(\lambda)$ $\left.\left.-K_{w}(\lambda)\right]\right)$. In a similar study, Baker and Smith [1982] adopted another equation of fit which comprises three independent parameters (instead of two here). Their equation for $450 \mathrm{~nm}$ is also graphically represented on Figure $7 a$.

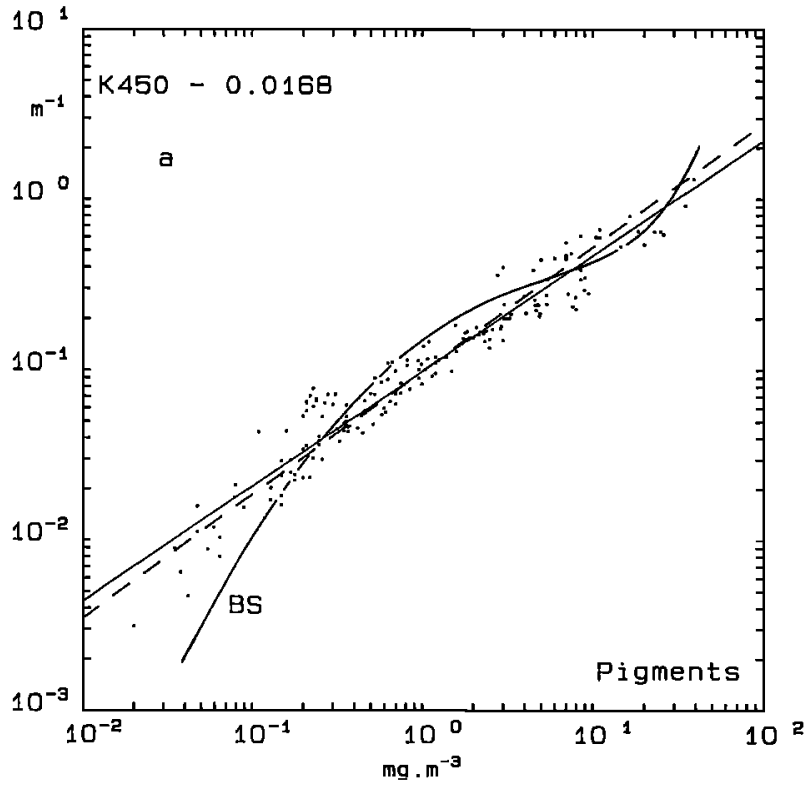

Fig. 7a. A log-log plot of the difference $K(450)-K_{w}(450)$ as a function of the pigment concentration for case $I$ waters only. The straight lines correspond to linear fits obtained by regression, whereas the curve comes from Baker and Smith [1982]. The case II waters, excluded from regression, are not shown.

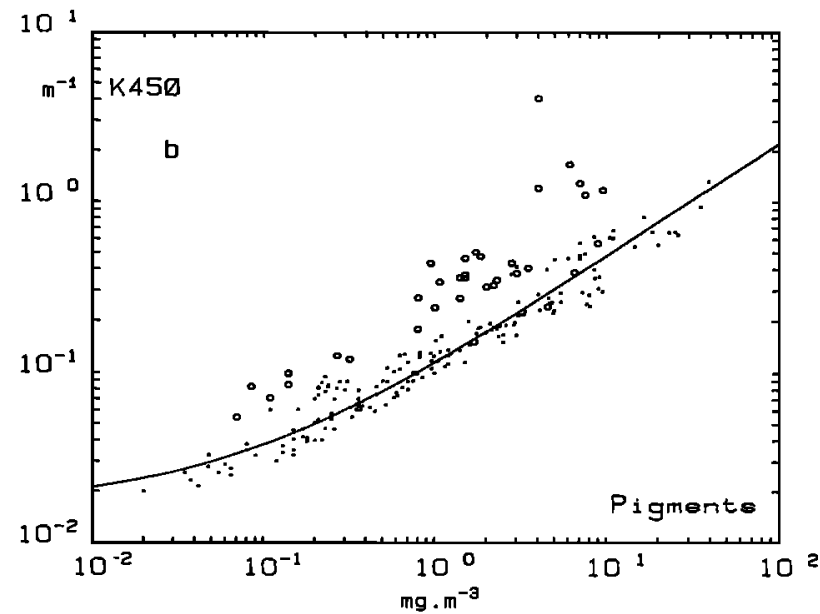

Fig. 7b. A $\log -\log$ plot of $K(\lambda)$ as a function of $C$, for $450-\mathrm{nm}$ wavelength. The circles represent dand $L 70$ and $L 72$ derived from the data of Lorenzen [1970, 1972]. The circles correspond to the products of the spectral model (see text and equations (11) and (4)).

With the $\chi_{c}(\lambda)$ and $e(\lambda)$ values of Table 2, equation (9) leads to the curves displayed on Figures $7 b-7 d$, together with the actual data. Examples for other wavelengths were also provided by Gordon and Morel [1983, Figures $7 a$ and $7 b$ ]. Figure $7 d$ exemplifies the bad situation encountered in the red, leading to uncertain values for $\chi_{c}$ and $e$. A somewhat arbitrary choice has to be made for these parameters when $\lambda>620 \mathrm{~nm}$. Some guidance, however, can be found by taking into account the absorption spectrum of living algal cells, as will be examined later on.

Equation (9), along with the tabulated coefficients in Table 2 , constitutes a model allowing $K(\lambda)$ spectra to be produced as a function of the pigment concentration. Such spectra are shown on Figure $5 b$ for $C$ going from 0 to $30 \mathrm{mg} \mathrm{m}^{-3}$. The general shape and evolution of the actual $K(\lambda)$ spectra (Figure $5 a$ ) are well reproduced by the modeled values. These are believed to be representative, on average, of the case I waters over the entire range of pigment concentrations expected for these waters.

The underlying hypothesis of this model deserves a comment. When writing (9), case I waters are considered as being, or restricted to, only a two-component system, the water itself

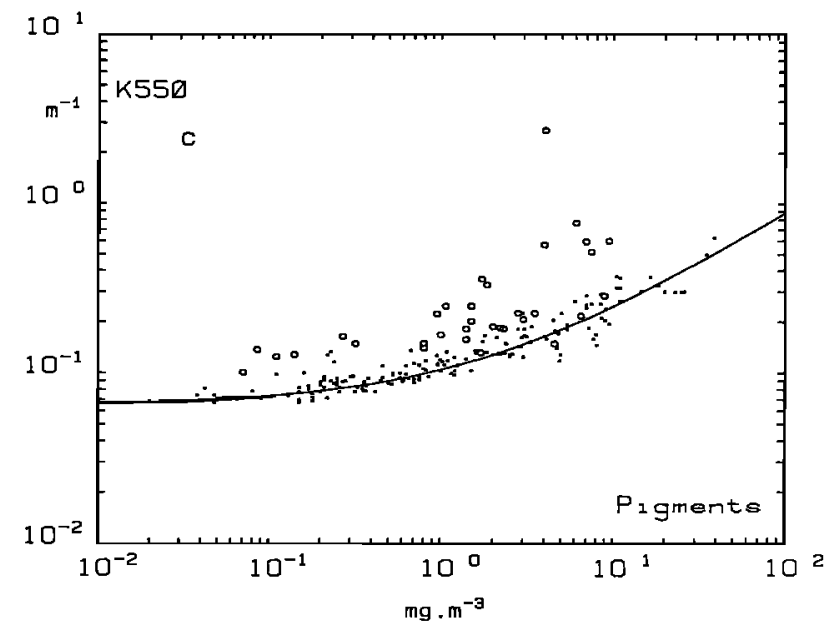

Fig. 7c. A log-log plot of $K(\lambda)$ similar to Figure $7 b$ except for the $550-\mathrm{nm}$ wavelength. 


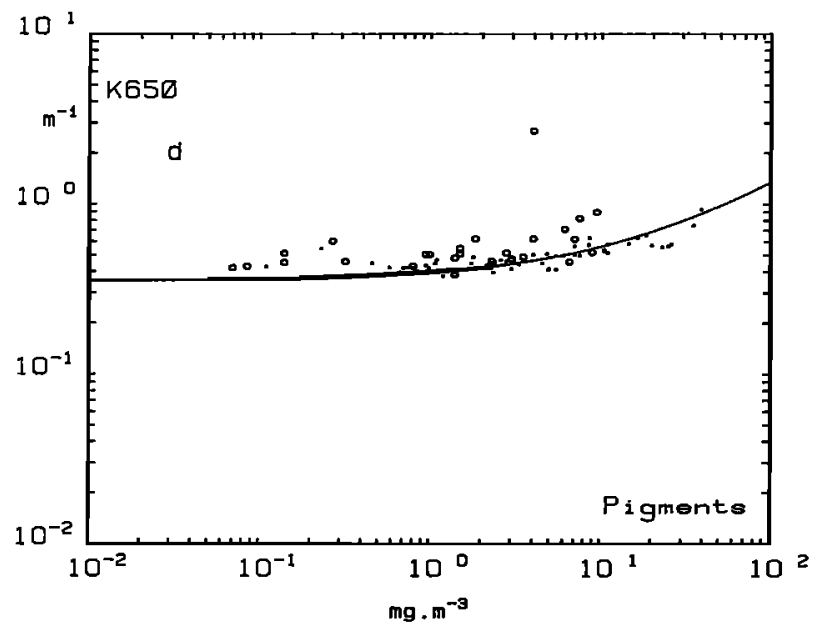

Fig. 7d. A $\log -\log$ plot of $K(\lambda)$ similar to Figure $7 b$ except for the 650 -nm wavelength.

(constant) and the (varying) biogenic component as quantified by the single index $C$, the $\mathrm{Chl} a+$ Pheo $a$ concentration. Inside the biogenic compartment the living phytoplanktonic cells and all the other phytoplankton derivative materials are pooled together, that is, the dissolved and particulate detrital matters. No attempt is made to identify separately the "subcomponents" inside the biogenic system. On the contrary, with a univocal correspondence between the $K(\lambda)$ spectra and $C$ it is implicitly admitted that certain correlations must exist among the subcomponents. In addition, the nonlinear biological effect, as depicted by the exponents $e(\lambda)$ in the $K(\lambda)-C$ relationships, implies that the biogenic compartment (and also its optical influence) is regularly and montonously changing with changing $C$, likely because the subcomponents mentioned above are themselves regularly varying in their relative proportions. These points will be examined later after several applications have been drawn from the model.

\section{Use of the Model to Predict the Euphotic Layer Depth}

The open question concerning the value of the exponent appearing in the $\bar{K}_{\mathrm{PAR}}-C$ statistical relationship in (5) can be reexamined inasmuch as the $K(\lambda)$ dependency on the pigment concentration $C$ is now established. It is possible to simulate the penetration of a realistic polychromatic radiant flux within a water body containing a variable amount of phytoplankton. The first step therefore consists of adopting the spectral composition of the incoming radiation $E_{0}(\lambda)$. A hundred spectral measurements effected above the surface when the sky was cloud free and the solar elevation was greater than $45^{\circ}$ were selected in view of computing an average spectrum. This spectrum is established with respect to either energy or amount of quanta, labeled $E_{0}{ }^{w}(\lambda)$ and $E_{0}{ }^{q}(\lambda)$, respectively, and in relative units (Figure 8 ). Convenient relative units are obtained by normalizing the spectral values with respect to the integral in such a way that

$$
\int_{400}^{700} E_{0}{ }^{w}(\lambda) d \lambda=1 \quad\left(\mathrm{~W} \mathrm{~m}^{-2}\right)
$$

which, with the spectral composition adopted, leads to

$$
\int_{400}^{700} E_{0}{ }^{9}(\lambda) d \lambda=2.744 \times 10^{18} \text { (quanta } \mathrm{m}^{-2} \mathrm{~s}^{-1} \text { ) }
$$

At a given depth $Z$ the spectral downwelling irradiance is computed through the expression

$$
E_{z}{ }^{i}(\lambda)=E_{0}{ }^{i}(\lambda) \exp [-K(\lambda) Z] \quad i=w \text { or } q
$$

in which $K(\lambda)$ varies with $C$ according to (9). (Note that (10) is an approximation to the extent that $K(\lambda)$, as apparent property, is slightly varying with $Z$, even in a homogeneous medium.)

When starting the computation with a given value of $C$, assumed to be constant along the vertical, the depth of the euphotic zone is still unknown. An iterative procedure is then used which constrains the ratio

$$
r=\int_{400}^{700} E_{z}^{i}(\lambda) d \lambda / \int_{400}^{700} E_{0}^{i}(\lambda) d \lambda
$$

to converge toward $r=0.01\left( \pm 10^{-5}\right)$ and consequently provides $Z_{e}{ }^{i}$. As a matter of fact, the $1 \%$ levels in terms of energy or of quanta differ slightly $\left(Z_{e}{ }^{w}\right.$ and $Z_{e}{ }^{q}$ in Table 3). The corresponding attenuation coefficients $\bar{K}_{\mathrm{PAR}}{ }^{i}$ for the photosynthetic radiations and averaged for the euphotic layer are straightforwardly obtained through (4).

The $Z_{e}{ }^{q}$ values with respect to quanta are plotted on Figure 2 along with the curve previously obtained by the regression analysis. There is a remarkable agreement between the two sets of data. In oligotrophic waters $\left(C<0.1 \mathrm{mg} \mathrm{Chl} a \mathrm{~m}^{-3}\right.$, $Z_{e}>90 \mathrm{~m}$ ) the modeled values progressively depart from the regression line. They are physically more realistic than the statistically derived values, since when $C$ tends toward zero, the model produces the limiting ideal case of optically pure water (with $Z_{e}^{q} \simeq 183 \mathrm{~m}$ ), a limit which cannot be produced when $Z_{e}$ is expressed as a power law of $C$, as in (1).

The $\bar{K}_{\mathrm{PAR}}{ }^{\mathrm{q}}$ values (Table 3 ) are plotted versus $C$ as circles on Figure $3 a$, together with the solid curve corresponding to (5). The modeled values nicely account for the exponent 0.428 resulting from, without being explainable by, the previous analysis. The nonlinear biological effect, transcribed by the exponents around 0.6 or 0.7 which appear in the $K(\lambda)-C$ relationships, is reinforced when taking into account the poly-

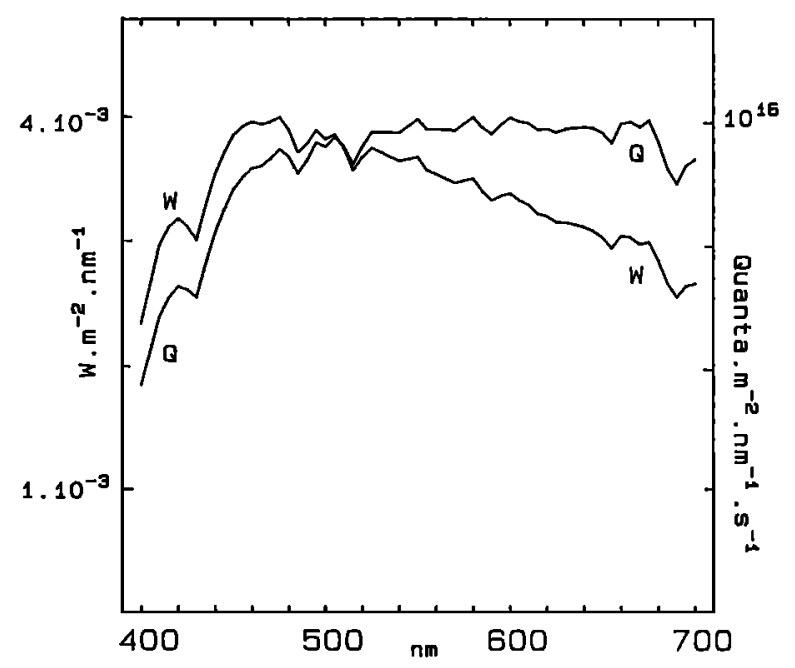

Fig. 8. Spectral values of the global (direct and diffuse) solar radiation on a horizontal surface and at sea level, as adopted in the model and used in (10), (14), and (21). These values are expressed in terms of $W \mathrm{~m}^{-2} \mathrm{~nm}^{-1}$ (left-hand ordinate scale and curve labeled $\mathrm{W}$ ) or of quanta $\mathrm{s}^{-1} \mathrm{~m}^{-2} \mathrm{~nm}^{-1}$ (right-hand ordinate scale and curve labeled Q). These curves are normalized (see text) with respect to the integrated value of energy over the 400 - to 700 -nm interval. 
TABLE 3. Values Resulting From the Use of the Spectral Model to Predict Euphotic Layer Depth

\begin{tabular}{|c|c|c|c|c|c|}
\hline $\begin{array}{c}C, \\
\mathrm{mg} \mathrm{m}^{-3}\end{array}$ & $\begin{array}{l}Z_{\mathrm{e}}^{w} \\
\mathrm{~m}\end{array}$ & $\begin{array}{c}\bar{K}_{\mathrm{PAR}^{k \prime}}{ }^{{ }^{\prime \prime}}{ }^{-1} \\
\end{array}$ & $\begin{array}{c}Z_{e}^{q} \\
\mathbf{m}\end{array}$ & $\underset{\mathrm{m}^{-1}}{\bar{K}_{\mathrm{PAR}^{q}},}$ & $\begin{array}{c}\text { Quanta-to-Joule } \\
\times 10^{18}\end{array}$ \\
\hline 30 & 8.06 & 0.5707 & 8.15 & 0.5650 & 2.835 \\
\hline 20 & 9.85 & 0.4675 & 9.90 & 0.4644 & 2.805 \\
\hline 10 & 13.75 & 0.3349 & 13.75 & 0.3348 & 2.748 \\
\hline 5 & 19.00 & 0.2431 & 18.90 & 0.2432 & 2.675 \\
\hline 3 & 24.05 & 0.1912 & 23.85 & 0.1930 & 2.630 \\
\hline 2 & 28.95 & 0.1589 & 28.55 & 0.1611 & 2.584 \\
\hline 1 & 39.55 & 0.1165 & 38.70 & 0.1190 & 2.514 \\
\hline 0.5 & 53.50 & 0.08605 & 51.90 & 0.08868 & 2.437 \\
\hline 0.3 & 66.15 & 0.06960 & 63.80 & 0.07213 & 2.390 \\
\hline 0.2 & 77.50 & 0.05941 & 74.50 & 0.06179 & 2.365 \\
\hline 0.1 & 98.75 & 0.04664 & 94.50 & 0.04874 & 2.335 \\
\hline 0.05 & 120.4 & 0.03825 & 114.5 & 0.04023 & 2.300 \\
\hline 0.03 & 135.3 & 0.03404 & 128.5 & 0.03583 & 2.290 \\
\hline 0.01 & 160.5 & 0.02868 & 152.5 & 0.03019 & 2.281 \\
\hline
\end{tabular}

chromatic nature of the submarine light field and its change with the pigment concentration. Therefore the exponent drops to about 0.4 when dealing with the entire spectrum and considering $\bar{K}_{\mathrm{PAR}}\left(0, Z_{e}\right)$.

\section{Chlorophyll-Specific Attenuation Coefficient} for Downwelling PAR Irradiance, " $\bar{k}_{c}$ "

The contribution of phytoplankton to the attenuation of downwelling PAR is described in (6) by a partial coefficient expressed as $\bar{k}_{c} C$, where $\bar{k}_{c}$ is the $\mathrm{Chl} a$-specific attenuation coefficient (the overbar indicates that it is a spectrally averaged coefficient). This coefficient has been widely used in the biological and primary production literature, even if it does not properly quantify the absorption capabilities of algae. Notwithstanding the debate concerning its significance, the value itself remains debatable. The empirical method used to determine $k_{c}$ from field experiments consists of studying $\bar{K}_{\mathrm{PAR}}$ along with $C$ and, when possible, to estimate $\bar{k}_{c}$ as the slope of linear regressions of $\bar{K}_{\mathrm{PAR}}$ versus $C$. From (5) the result is

$$
\bar{k}_{c}=d \bar{K}_{\mathrm{PAR}} / d C=0.0518 C^{-0.572}
$$

for oceanic case I waters. According to this expression, $\bar{k}_{c}$ regularly decreases with increasing pigment concentration from approximately $0.2 \mathrm{~m}^{2}(\mathrm{mg} \mathrm{Chl})^{-1}$ if $C \simeq 0.1 \mathrm{mg} \mathrm{m}^{-3}$ to 0.007 if $C$ is close to $30 \mathrm{mg} \mathrm{m} \mathrm{m}^{-3}$ (Figure 9). It is interesting to remark that contradictory results which have been previously published can be reconciliated. Tyler [1975], Morel and Prieur [1977], and Dubinsky and Berman [1979] found $\bar{k}_{c}=0.0415$, 0.014 , and $0.0067 \mathrm{~m}^{2}(\mathrm{mg} \mathrm{Chl} a)^{-1}$ for waters with about 1.5 , 10 , and $35 \mathrm{mg} \mathrm{Chl} a \mathrm{~m}^{-3}$, respectively. These values are perfectly accounted for by the above relationship. The two values proposed by Smith and Baker [1978] are 0.091 and 0.016 $\mathrm{m}^{2}(\mathrm{mg} \mathrm{Chl} a)^{-1}$ if $C<0.8$ or $C>0.8 \mathrm{mg} \mathrm{Chl} a \mathrm{~m}^{-3}$, respectively. According to (12), these values are found for $C=0.37$ and $7.8 \mathrm{mg} \mathrm{m}^{-3}$, in agreement with the actual data used in the study by Smith and Baker. Widely spread $\bar{k}_{\mathrm{c}}$ values have been obtained in lakes [Weidemann and Bannister, 1986; Kirk, 1983, Table 9.1] which are not explained by (12), which is likely because these lake waters are not case I oceanic waters.

It is clear that a mathematical expression such as (12) loses its physical meaning when $C$ tends toward zero or toward extremely high values. Its applicability has to be restricted to the range within which it has been established (say $0.03-30 \mathrm{mg}$ Chl $a \mathrm{~m}^{-3}$ ).

Spectral Values of the Chl-Specific Attenuation for Downwelling Irradiance $k_{c}(\lambda)$

As above, the spectral values of this coefficient can be defined and computed as the derivative of $K(\lambda)$ with respect to the pigment concentration $C$. From (9) it follows that

$$
k_{c}(\lambda)=d K(\lambda) / d C=e(\lambda) \chi(\lambda) C^{e(\lambda)-1}
$$

The spectral $k_{c}(\lambda)$ values for some selected $C$ values are presented in absolute units $\left(\mathrm{m}^{2} \mathrm{mg}^{-1} \mathrm{Chl} a\right)$ in Figure $10 a$ and in relative units, after they have been normalized at $400 \mathrm{~nm}$, in Figure $10 b$. When $C$ is given the highest values, the $k_{c}(\lambda)$ coefficients exhibit their lowest values within the entire spectral range. As soon as $C$ decreases, all the $k_{c}(\lambda)$ values are dramatically enhanced, owing to the negative exponents applied to $C$. With these exponents slightly depending on the wavelength the shape of the $k_{c}(\lambda)$ curves also changes with changing concentration as evidenced by the normalization (Figure 10b).

Restricting by now the comments to the spectral domain at

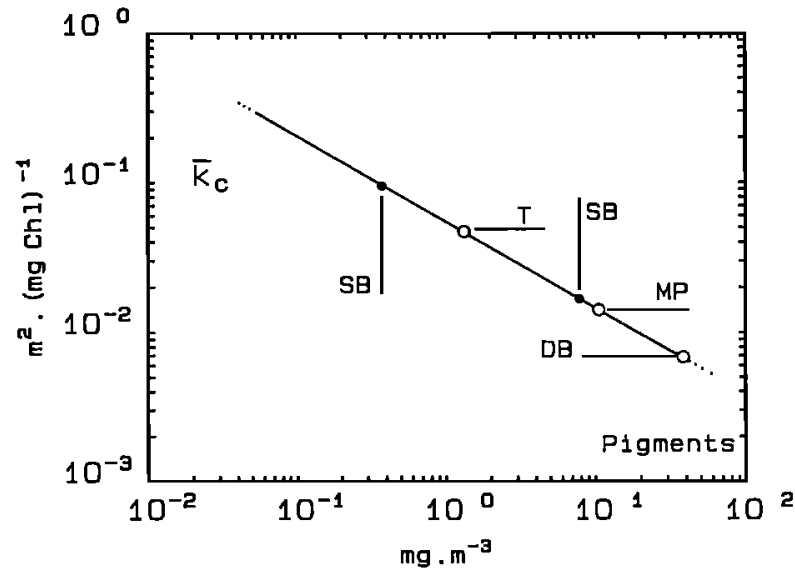

Fig. 9. The chlorophyll-specific attenuation coefficient for downwelling PAR (400-700 $\mathrm{nm}$ ) plotted as a function of the mean chlorophyll concentration, according to (12). Particular $\bar{k}_{c}$ values, observed by the different authors Tyler [1975] (T), Smith and Baker [1978] (SB), Morel and Prieur [1977] (MP), and Dubinsky and Berman [1979] (DB) are also pointed out (see text). 


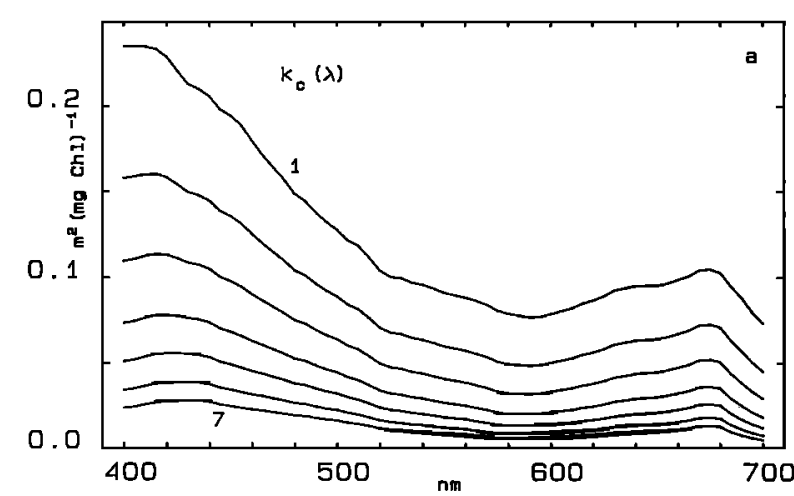

Fig. 10a. Spectral values of the chlorophyll-specific attenuation coefficient for downwelling irradiance computed according to (13) and for case I waters with the following pigment concentrations: $0.03,0.1$, $0.3,1,3,10$, and $30 \mathrm{mg} \mathrm{m}^{-3}$ for the curves labeled $1-7$, respectively.

$400-650 \mathrm{~nm}$, where $\chi(\lambda)$ and $e(\lambda)$ are statistically well established, the following can be pointed out:

1. For very low pigment content $\left(C \leq 0.03 \mathrm{mg} \mathrm{m}^{-3}\right)$ the $k_{c}(\lambda)$ spectrum is essentially featureless, with a sharp decrease from the blue end, followed by an almost flat portion in the green-yellow domain. Such a curve tends to resemble that of purely detrital materials [Yentsch, 1962; Kishino et al., 1986] and is similar to the absorption spectrum calculated by Kiefer and Soohoo [1982] for the material which covaries with pheopigments.

2. For high pigment content $\left(>10 \mathrm{mg} \mathrm{m}^{-3}\right)$, significant features appear on the $k_{c}(\lambda)$ spectrum, essentially a broad "bump" centered at about $435 \mathrm{~nm}$, a minimum at $580 \mathrm{~nm}$, and a smooth ascending slope from 580 toward $630 \mathrm{~nm}$. This shape is very comparable to that of $a^{*}(\lambda)$, the Chl $a$-specific absorption spectra determined for living algal cells grown in culture [Bricaud et al., 1983, 1988; Bricaud and Morel, 1986]. In addition, the absolute values in the blue $\left(k_{c}(435)=\right.$ $0.039-0.028 \mathrm{~m}^{2} \mathrm{mg}^{-1} \mathrm{Chl} a$, when $C$ goes from 10 to $30 \mathrm{mg}$ $\mathrm{m}^{-3}$ ) are within the range of the $a^{*}(435)$ values obtained for algae in culture. An "averaged" absorption spectrum computed for 14 species (references above) is shown on Figure $10 c$.

This is the rationale for deciding the best values for $\chi(\lambda)$ and $e(\lambda)$ in the 620 - to $700-\mathrm{nm}$ domain where, as said before, the confidence in the statistical treatment fails. It is believed that in eutrophic waters the influence of biogenic detritus is reduced compared to that of living algae and that an inverse situation is to be found in oligotrophic waters. Supporting

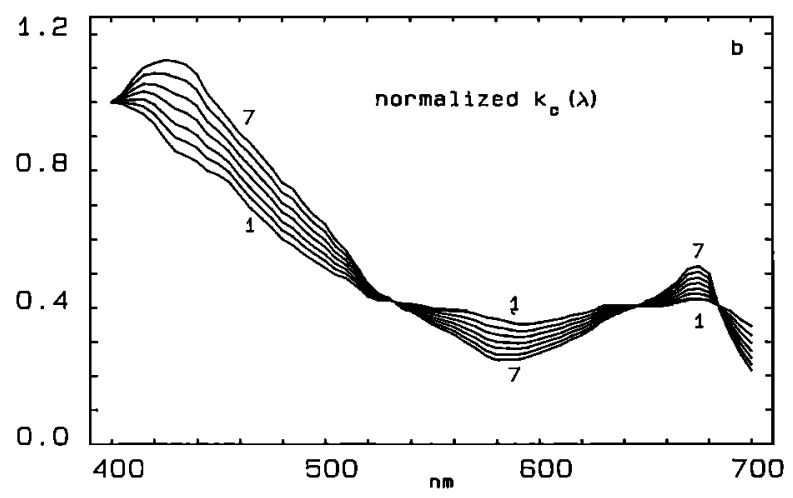

Fig. 10b. Same as for Figure 10a, except that the spectral values are normalized at $\lambda=400 \mathrm{~nm}$.

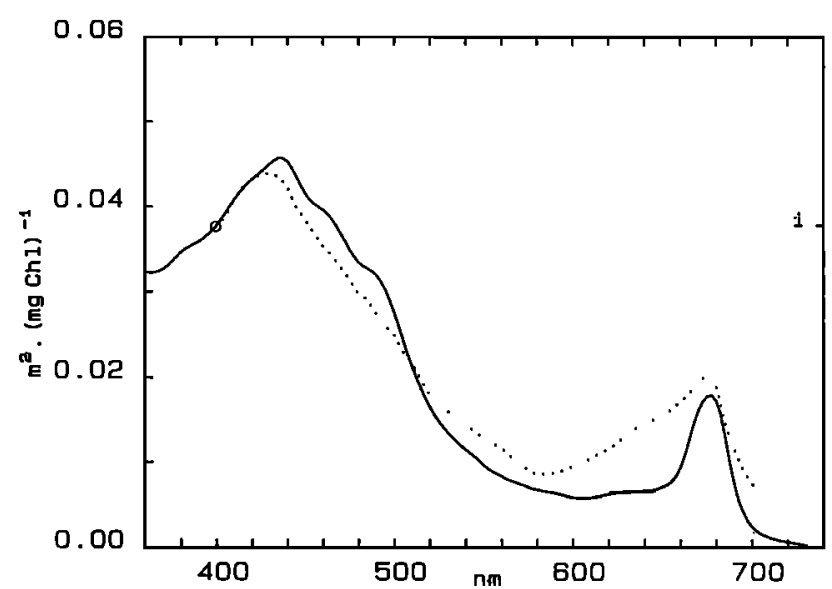

Fig. 10c. Spectral values of the Chl-specific attenuation coefficient for downwelling irradiance when the pigment concentration is $30 \mathrm{mg}$ $\mathrm{m}^{-3}$ (dotted curve, redrawn from Figure $10 a$ and normalized at $\lambda=400 \mathrm{~nm}$, right-hand scale). The solid curve corresponds to the spectral values of the Chl-specific absorption coefficient $a^{*}(\lambda)$ for algae grown in culture (left-hand scale). This curve was obtained by averaging the spectra determined for 14 species: three by Bricaud et al. [1983], three by Bricaud and Morel [1986] and eight by Bricaud et al. [1988] (data for cyanobacteria have been disregarded when averaging).

arguments will be provided later. Under this assumption the $\chi(\lambda)$ and $e(\lambda)$ values determined in the red domain are slightly readjusted in such a way that they can reproduce the magnitude of the red peak $(675 \mathrm{~nm})$ exhibited by the algae in culture. The adopted values are consistent with the results of a statistical study made by Austin and Petzold [1986] which is discussed later (see also Figure 19b). It remains, nevertheless, that accurate measurements in this part of the spectrum are needed to ascertain the values which are proposed here.

"Quanta-to-Joule" Ratio in an Aquatic Environment and Spectral Composition of the Remnant Light as Derived From the Model

By using (9) and (10) the "quanta-to-joule" ratio can be computed at any depth according to

$$
\text { quanta } J^{-1}=\int_{400}^{700} E_{z}{ }^{q}(\lambda) d \lambda / \int_{400}^{700} E_{z}{ }^{w}(\lambda) d \lambda
$$

With the daylight spectral composition in Figure 8 this ratio is equal to 2.744 quanta $\mathrm{J}^{-1}$ at the surface. It is hereinafter modified with increasing depth and depends on the spectral composition of the remnant submarine light, which itself depends on the pigment concentration $C$. The computations effected for $Z=Z_{e}{ }^{q}$ lead to the values given in Table 3 and to the curve which is plotted on Figure 11, redrawn from Morel and Smith [1974]. The modeled curve provides an appropriate explanation to the previously published experimental findings. As expected, this curve which stands for $Z=Z_{e}{ }^{q}$ forms an envelope to the field data obtained at depths less than $Z_{e}{ }^{q}$; at these depths the optical filtering by the water is less pronounced, and the departure of the ratio from its surface value is less marked than at the bottom of the euphotic layer.

The spectral change of the downwelling irradiance is illustrated by Figures $12 a-12 d$, where $C$ is given discrete values ranging from 0.03 to $30 \mathrm{mg} \mathrm{m}^{-3}$. In Figures $12 a$ and $12 b$ the depth is that of the euphotic layer (Table $3, Z_{e}{ }^{q}$ values); in 


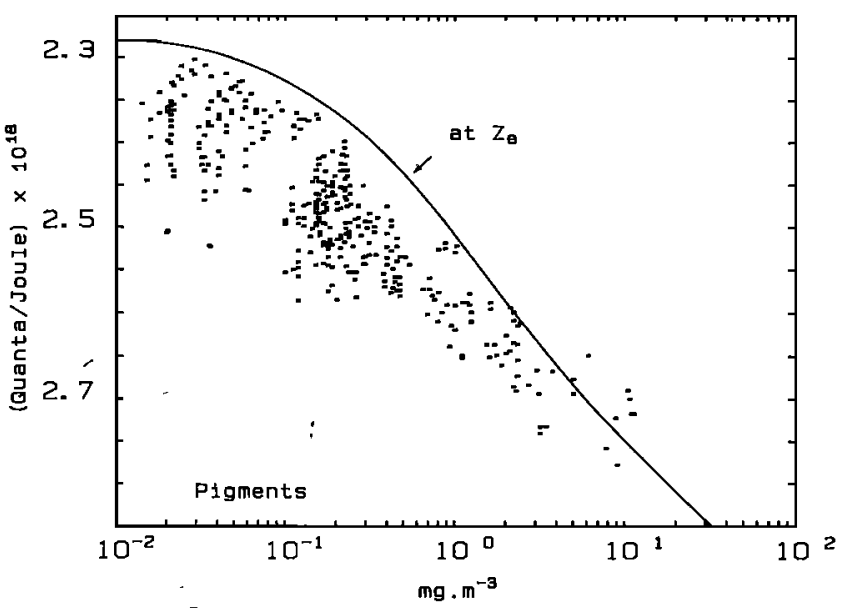

Fig. 11. Quanta-to-joule ratio for the downwelling solar radiation as a function of the pigment concentration within the water body. The dots are for experimental determinations at different depths smaller than the euphotic depth (redrawn from Morel and Smith [1974]). The curve results from computations according to (14), effected for depths equal to those of the euphotic layer.

Figures $12 c$ and $12 d$ the depth is where the photon flux is reduced to $10 \%$ of this value at the surface, denoted $Z_{e / 2}{ }^{q}$ (this depth is computed through equation (11) and by forcing the ratio $r$ to converge toward 0.1). Because of the spectral narrowing effect which increases with increasing depth the mideuphotic depth $Z_{e / 2}{ }^{q}$ is always less than half of $Z_{e}^{q}$. The modeled spectra, in terms of energy (Figures $12 a$ and $12 c$ ) or quanta (Figures $12 b$ and $12 d$ ), account very nicely for the spectra measured in different case I waters (see, e.g., Morel [1978]). In addition to the narrowing effect these spectra show the well-known shift in the spectral distribution of the submarine light, from blue $(470 \mathrm{~nm})$ in oligotrophic waters to green-yellow $(570-580 \mathrm{~nm})$ in eutrophic waters. The switch from blue to green ambiance occurs around the hinge value of $2 \mathrm{mg} \mathrm{m}^{-3}$ (the minimum at $515 \mathrm{~nm}$ which notches the spectrum for this concentration originates from the Fraunhofer "b" lines). These computations and figures are made under the assumption of a constant pigment concentration within the water column. There are no particular difficulties in considering irregular vertical distributions.

By virtue of the normalization by their integrals (in photons) these spectra are directly comparable in magnitude, and interesting points emerge from such a representation. By considering, for instance, the oligotrophic waters in Figures $12 a$ and $12 b$ it appears that if only $1 \%$ of the incident photons remain for the entire PAR domain, more than $3 \%$ of the "blue photons" or more than $4 \%$ of the energy are still present at this depth. The same remark can be repeated in the case of eutrophic waters and for "green photons." This pitfall in the definition of the euphotic depth has to be kept in mind when studying the deep chlorophyll maximum and the production of such ecosystems.

\section{Spectral Reflectance $R(\lambda)$ of Case I Waters as Predicted by the Model}

The reflectance $R$ is defined as the ratio of upwelling to downwelling irradiance at a given depth. This ratio at depth zero (meaning just below the surface) is the appropriate parameter which describes how the incident solar flux is returned toward the atmosphere. The spectral values $R(\lambda)$ are related to the water content. Therefore the capabilities of remote sensing techniques rest on an adequate predictability of the $R(\lambda)$ dependence on the pigment content $C$ when dealing with case I waters.

It has been shown that within a good approximation, $R$ is expressed as

$$
R=0.33 b_{b} / a
$$

at least when the ratio of the backscattering of the water, $b_{b}$, to its absorption a remains $\ll 1$ [Gordon et al., 1975; Prieur, 1976; Morel and Prieur, 1977]. The numerical factor 0.33 which merges several intricate influences (the volume scattering function of the water and the above-water and in-water radiance distribution) is only slightly variable with the illumination conditions [Kirk, 1981].

In view of using the $K-C$ relationships previously established, the above expression has to be transformed into

$$
R=(0.33 / u)\left(b_{b} / K_{d}\right)
$$

where the subscript $d$, abandoned before, is reintroduced. This first approach postulates that $K_{d}$ is linearly related to $a$ through $a=u K_{d}$, a condition which will be relaxed hereinafter. The exact meaning of $u$, seen now as a constant, will be explicit when the assumption of linearity is abandoned. The backscattering coeflicient is split into

$$
b_{b}=\frac{1}{2} b_{w}+\tilde{b}_{b} b
$$

where the constant contribution of the water appears (half of the molecular scattering $b_{w}$ ) and the variable contribution of the other particulates are expressed as the product of the scattering coefticient $b$ and the dimensionless backscattering ratio $\tilde{b}_{b}$. At this stage the first question is to establish the link between $b$ and $C$, and the second question is to estimate $\tilde{b}_{b}$ and express its spectral dependence.

The scattering coefficient at $550 \mathrm{~nm}$ measured in situ has been studied along with the pigment concentration determined on samples taken at the same depths [Morel, 1980; Gordon and Morel, 1983]. For case I waters only and within 3 orders of magnitude in $C$ a general relationship has been obtained through regression analysis (506 data, $\left.r^{2}=0.90\right)$ :

$$
b_{550}=0.30 C^{0.62}
$$

Such a power law with an exponent less than one demonstrates that in oligotrophic waters the scattering by particulates is relatively higher than in eutrophic waters. The "chlorophyll-specific scattering" coefficient, defined as $b / C$, decreases from 1.15 to $0.10 \mathrm{~m}^{2}(\mathrm{mg} \mathrm{Chl})^{-1}$ when $C$ goes from 0.03 to $20 \mathrm{mg} \mathrm{m}^{-3}$. This regular trend constitutes a supplementary argument in favor of a reinforced relative role of detritus when the algal crop diminishes [Morel, 1987].

The choice of the spectral dependence of the $\tilde{b}_{b}$ value results from the following considerations:

1. The particle scattering has been shown to vary approximately with $\lambda^{-1}$ [Morel, 1973]. Such a dependency is expected when the size distribution function for the particles obeys a Junge law with the exponent -4 . This law is generally thought to be representative of most natural waters, at least for the detrital fraction of the particle population. On this continuum a peak may be superimposed when living algae, with a relatively narrow size distribution, are present.

2. The shape of the volume scattering function for marine 

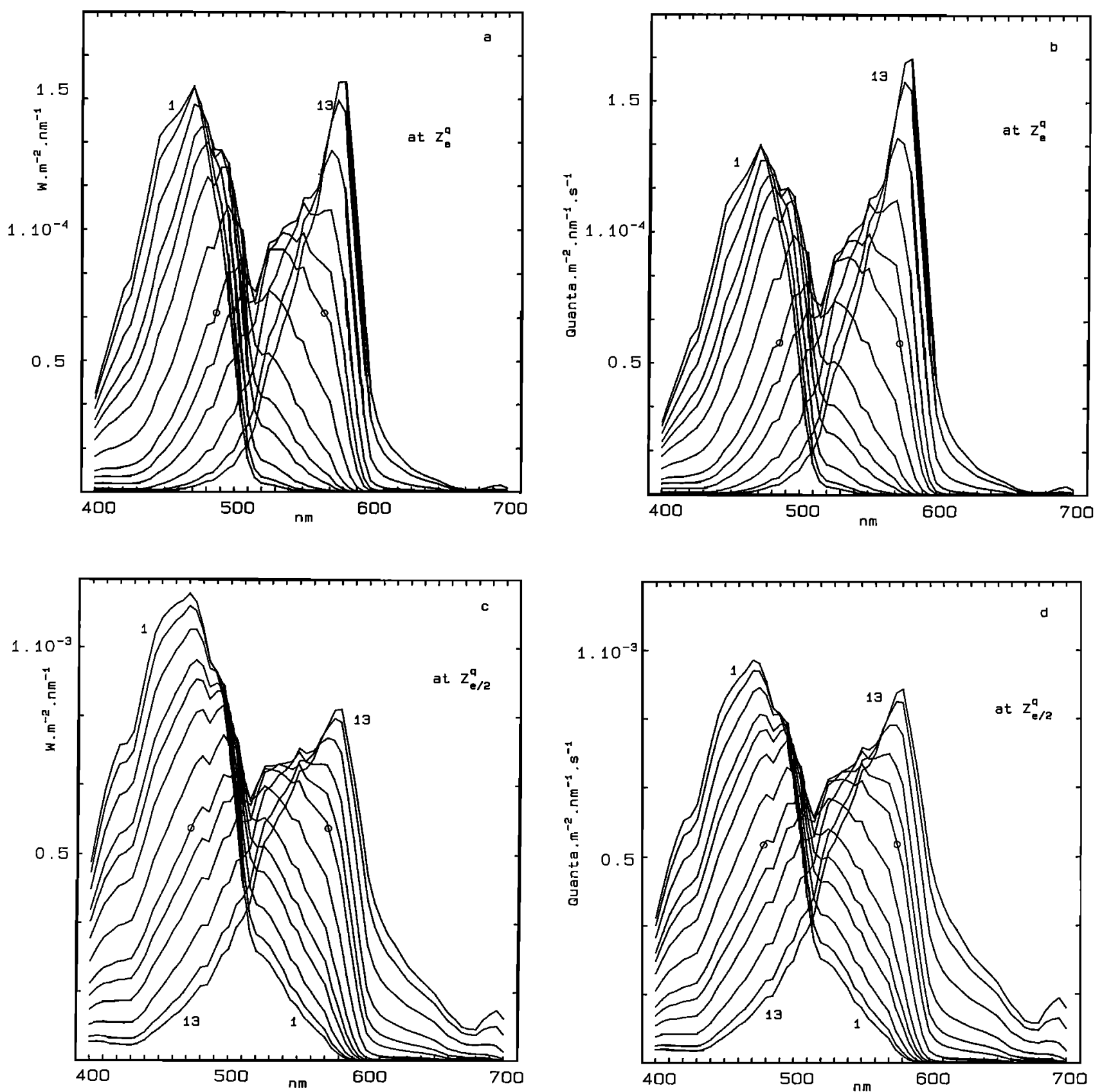

Fig. 12. (a) and (b) Spectral distribution of the downwelling solar radiation reaching the bottom of the euphotic layer or $(c)$ and $(d)$ the mideuphotic depth. For Figures $12 a$ and $12 c$ the spectral downwelling irradiance values are given in units of energy (W m $\mathrm{Wm}^{-2} \mathrm{~nm}^{-1}$, given that the total energy between 400 and $700 \mathrm{~nm}$ is $1 \mathrm{~W} \mathrm{~m}^{-2}$ at null depth); for Figures $12 b$ and $12 d$ the spectral values are in relative quanta (quanta $\mathrm{m}^{-2} \mathrm{~nm}^{-1} \mathrm{~s}^{-1}$, given that the total amount of quanta between 400 and $700 \mathrm{~nm}$ and at zero depth is unity per square meter and per second. The spectral distributions depend on the mean pigment concentration within the layer considered; from 1 to 13 the pigment concentration increases according to the sequence $0.03,0.05,0.1,0.2,0.3, \cdots, 30 \mathrm{mg} \mathrm{m}^{-3}$. The spectra for $2 \mathrm{mg} \mathrm{m}^{-3}$ are identified by circles.

particles (again predominantly of detritic nature) leads to an almost constant $\tilde{b}_{b}$ value of about $2 \%$ [Morel, 1973].

3. Algal cells exhibit very low $\tilde{b}_{b}$ values [Bricaud et al., 1983], as is fully supported by theory [Bricaud and Morel, 1986]. The spectral variations in $\tilde{b}_{b}$ for algae, mainly ruled by algal pigment absorption, can be neglected.

By taking into account these results the term $\tilde{b}_{b}$ in equation (17) can be modeled as the sum of (1) a constant term, whatever the wavelength and the concentration $C$, which is put equal to $0.2 \%$, and (2) a term varying as $\lambda^{-1}$ and also varying in magnitude with $C$. This term is put equal to $2 \%$ when $\lambda=550 \mathrm{~nm}$ and when $C=10^{-2} \mathrm{mg} \mathrm{m}^{-3}$; it is allowed to decrease proportionally to $\log _{10} C$ and is zero for $C=10^{2} \mathrm{mg}$ $\mathrm{m}^{-3}$ (see inset in Figure 13). Accordingly, $b_{b}$ is numerically expressed as

$$
\tilde{b}_{b} b=0.30 C^{0.62}\left[2.10^{-3}+2.10^{-2}\left(\frac{1}{2}-\frac{1}{4} \log C\right)(550 / \lambda)\right]
$$

The rationale of this modeling is to obtain a progressive change from an oligotrophic situation where detritus are relatively more abundant (detrital particles, characterized by $\tilde{b}_{b}=$ 


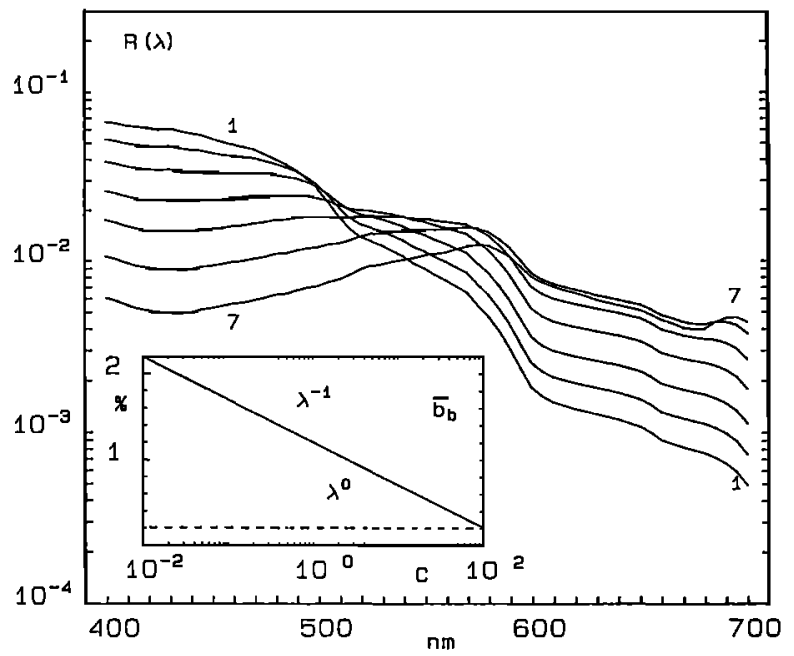

Fig. 13. Modeled reflectance spectra for varying mean pigment concentration in case I waters and at null depth. From curves 1 to 7 , the pigment concentrations are $0.03,0.1,0.3,1,3,10$, and $30 \mathrm{mg} \mathrm{m}^{-3}$ as in Figure 10a.

$2 \%$ and a $\lambda^{-1}$ scattering dependency) to eutrophic situation where algal cells are the predominant particles, with low $\tilde{b}_{b}$ $(0.2 \%)$ and practically no spectral dependency.

With the above expression for $\tilde{b}_{b} b$, the $b_{w}(\lambda)$ values of Morel [1974] (see also Smith and Baker [1981]), and the relationships between $K(\lambda)$ and $C$ (equation (9) and Table 2), a first approximation of the spectral reflectance $R_{1}(\lambda)$ can be obtained through equation (16) (every $5 \mathrm{~nm}$ ). For this first approximation (i.e., the first loop in the iteration) the factor $u$ is put equal to $u_{1}=0.75$. Then a more accurate value of $R(\lambda)$ can be obtained by an iterative procedure which allows $u$ to be progressively adjusted according to an exact relationship which links $a, K_{d}$, and $R$ (see, e.g., Prieur and Sathyendranath [1981]):

$$
a=K_{d} u=K_{d}\left(1-R+\frac{1}{K_{d}} \frac{d R}{d Z}\right) \frac{\mu_{d} \mu_{u}}{R \mu_{d}+\mu_{u}}
$$

The average cosine for the downwelling radiant field $\mu_{d}$ is the ratio of downwelling irradiance to scalar downwelling irradiance. For the surface layer, $\mu_{d}$ depends mainly on the solar elevation; an average value is adopted for $\mu_{d}$ equal to 0.90 . The average cosine for upwelling light $\mu_{u}$ (defined as above but with respect to upwelling irradiances) is rather constant and close to 0.40 [Kirk, 1983]. The change of $R$ with depth is very small so that $d R / d Z$ can be neglected; thus the above expression becomes

$$
a(\lambda)=K_{d}(\lambda) \frac{0.90[1-R(\lambda)]}{1+2.25 R(\lambda)}=K_{d}(\lambda) u_{2}(\lambda)
$$

Since the first iteration has provided a first set of $R_{1}(\lambda)$ values, $u_{2}(\lambda)$ can be computed. Therefore the above assumption $\left(u_{1}=\right.$ constant) can be relaxed by using $u_{2}$ to replace $u_{1}$ in (16). Steady values of $R(\lambda)$ are produced within three loops in this iterative process.

The reflectance spectra for pigment contents $C$, varying from 0.03 to $30 \mathrm{mg} \mathrm{m}^{-3}$, are presented on Figure 13. They nicely account, in shape and magnitude, for the actual $R(\lambda)$ spectra measured in case I waters [see Morel and Prieur, 1977, Figure 6] except obviously for the fluorescence emission at
$685 \mathrm{~nm}$, which is not presently modeled. Other comparisons between modeled and measured reflectances (at these wavelengths which correspond to the coastal zone color scanner channels) have shown a satisfactory agreement [Bricaud and Morel, 1987]. In remote sensing, the most sensitive pigment algorithm which can be envisaged is that which involves a couple of wavelengths in the vicinity of the $R(\lambda)$ minimum in the blue and the $R(\lambda)$ maximum in the yellow green, which develop when $C$ increases. This method was successfully applied to the coastal zone color scanner data (with the 443- and the 550-nm channels) and is envisaged for future sensors. An example of what could be a case I waters algorithm, as derived from the present model, is provided in Figure 14 for the wavelengths $440-565 \mathrm{~nm}$. The curve shown in this figure corresponds to the analytical expression

$$
\log _{10}(C / 0.4)=-2.144 \log _{10}(\rho / 2)-1.766\left[\log _{10}(\rho / 2)\right]^{3}
$$

which has been adjusted to fit the modeled data and could be used to retrieve $C$ from $\rho=R(440) / R(565)$.

\section{Solar Heating Due to Visible Radiations in Relation to Pigment Concentration Within the Upper Layer}

Owing to the high values of absorption by the water itself, the solar infrared radiation (about $57 \%$ of the total radiation) is rapidly absorbed within a few tens of centimeters. The varying pigment concentration in case I waters does not significantly modify this figure. The heating rate associated with solar IR can thus be treated separately from that resulting from visible $(400-700 \mathrm{~nm})$ radiations which are much more penetrative but also much more sensitive to the water content, namely, to the pigment content. The results below only deal with the visible radiation absorption and are obtained under the assumption that the impinging flux above the surface has been corrected for Fresnel reflection at the interface and for diffuse reflection from the upper layer. This last term can be computed from the $R(\lambda)$ values, once integrated over the whole visible domain, and then multiplied by the factor 0.54 [Austin, 1974], which accounts for the internal reflection of the upwelling flux.

In the visible domain the absorbed radiation is essentially

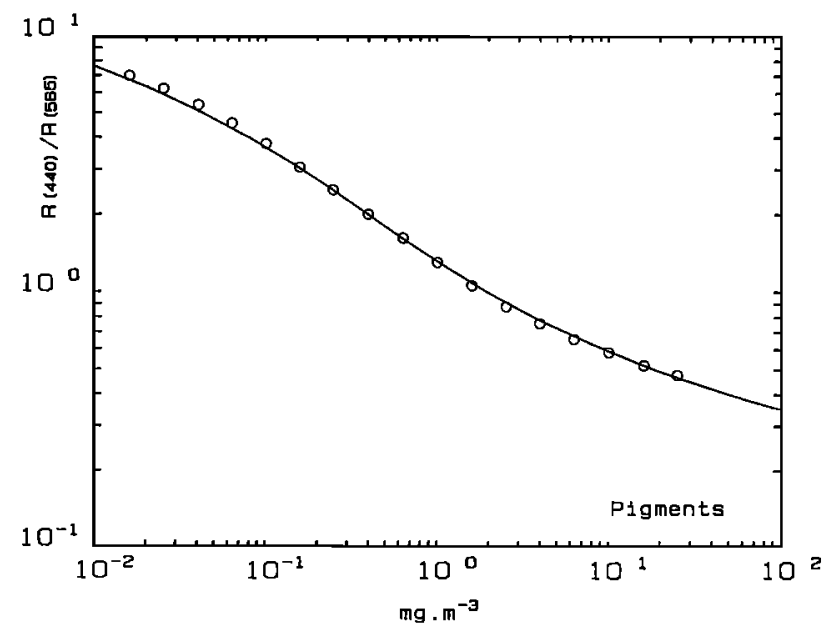

Fig. 14. Ratio of the reflectances at 440 and $565 \mathrm{~nm}$ and at null depth, as a function of the pigment concentration. The circles stand for the values computed for case I waters according to the reflectance model (see text). 


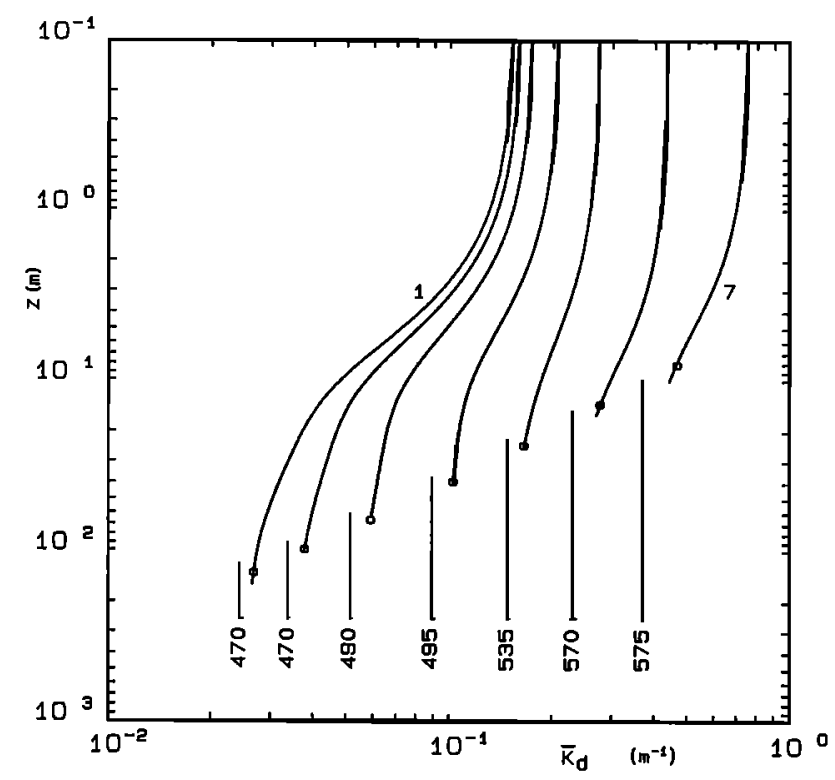

Fig. 15. Local values of the attenuation coeflicient for downwelling visible $(400-700 \mathrm{~nm})$ radiation $R_{d}(Z)$ as a function of depth. The different profiles are for homogeneous water bodies having various pigment concentrations, ranging from 0.03 (curve 1 ) to $30 \mathrm{mg} \mathrm{m}^{-3}$ (curve 7), as in Figure 13. The $\bar{K}_{d}\left(Z_{e}\right)$ values at the bottom of the euphotic layer are shown as circles, and the asymptotic values at : greater depths are shown as vertical lines. The central wavelength of the remnant light is also given (in $\mathrm{nm}$ ).

converted into heat, even if energy storage occurs within the organic compounds created through photosynthesis. The amount of such stored energy (reconverted into heat elsewhere and with delay) may hardly exceed $2 \%$ of the visible incident radiation (Morel [1978], Platt [1986], and this study). This small fraction, which will be examined later because of its geochemical impact, can be safely neglected when the geophysical phenomenon of solar heating is under scrutiny. Note also that the fluorescence pathway leads almost instantaneously to heating.

A bulk representation of the upper ocean heating by visible radiation has already been given above. In addition to its biological significance the euphotic layer is also that layer inside which $99 \%$ of the incident photons have disappeared by absorption. Therefore equation (1) with Figure 1 (and $Z_{e}{ }^{w}$ values in Table 3) provide straightforward information about the thickness of the whole heated layer and its possible variations, from less than $10 \mathrm{~m}$ to more than $100 \mathrm{~m}$ in case I waters ranging from eutrophic to oligotrophic. This global result has to be analyzed by studying the heating rate as a function of depth and pigment concentration.

At a given depth within a horizontally homogeneous water body the rate of radiant energy converted into heat is expressed as the divergence of the net radiative flux so that the temperature change $d T / d t$ is

$$
\frac{d T}{d t}=-\frac{d\left(E_{d}-E_{u}\right)}{d Z} \frac{1}{\rho c_{p}}
$$

with $\rho$ the in situ density, $c_{p}$ the specific heat, and $E_{d}$ and $E_{u}$ the downward and upward irradiances, respectively, (the vertical divergence of turbulent heat flux is assumed to be zero). The divergence of the radiative flux is also expressed as

$$
d\left(E_{d}-E_{u}\right) / d Z=-a E^{\circ}
$$

where $a$ is the local absorption coefficient and $E^{\circ}$ is the scalar irradiance at the depth in question. The quantities studied here, however, are neither $E^{\circ}$ nor $a$ but $E_{d}$ and $K_{d}$ (the subscript $d$ for downwelling is reintroduced for this part). Among these quantities a rigorous relationship exists (see, e.g., Preisendorfer [1976]):

$$
a \stackrel{E}{E}=K_{d} E_{d}\left[1-R\left(K_{u} / K_{d}\right)\right]
$$

where $K_{w}$ is the attenuation coefficient for upwelling irradiance. In general, $K_{u}$ does not significantly differ from $K_{d}$ and $R$ remains small; therefore (21) can safely be simplified to allow the heating rate to be computed from known parameters:

$$
d T / d t \simeq \bar{K}_{d} \bar{E}_{d}(1-\bar{R})\left(\rho c_{p}\right)^{-1}
$$

where $\bar{K}_{d}, \bar{E}_{d}$, and $\bar{R}$ represent the averaged quantities over the spectral domain 400-700 $\mathrm{nm}$. According to the reflectance model presented above, the corrective term $(1-\bar{R})$ ranges between 0.995 and 0.977 for decreasing pigment concentration and could be neglected as well.

At given depth $Z$ and for a given pigment concentration $C$ the downward flux can be obtained by using the $\chi(\lambda)$ and $e(\lambda)$ values listed in Table 2 and then by integrating (10) (with $i=w)$ to obtain $\bar{E}_{d}(Z, C)$. The "local" coefficient $\bar{K}_{d}(Z, C)$ has to be computed through the expresssion by which it is defined:

$$
\bar{K}_{d}(Z, C)=-d \log \bar{E}_{d}(Z, C) / d Z
$$

which is numerically computed with $d Z=5 \mathrm{~cm}$. On Figure 15 are presented the vertical profiles of $\bar{K}_{d}$ for various values assigned to the pigment concentration. Each profile exhibits a strong decrease in the first $10 \mathrm{~m}$ (due to absorption of the red radiations) and, at greater depth, tends progressively toward an asymptotic value (when the remnant light tends to become monochromatic). The different profiles are widely spread out according to the $C$ value used as input.

For varying depths and pigment concentrations the quantity

$$
\int_{400}^{700} E_{d}(Z, C, \lambda) K_{d}(Z, C, \lambda) d \lambda
$$

can be computed, and absorption can be estimated. To preserve that generality, the results are normalized by the incident energy at $Z=0$; therefore the units are simply $\mathrm{m}^{-1}$ (energy absorbed per volume at a depth $Z$ divided by incident energy per area at $Z=0$ ). On Figure 16 are shown the absorbing rates profiles as they result from this computation for three values of the pigment concentration, assumed constant with respect to depth. After dividing by $\rho c_{p}\left(4.2 \mathrm{MJ} \mathrm{m}^{-3}\right.$ ${ }^{\circ} \mathrm{K}^{-1}$ ) the heating rates are obtained as kelvins for $1 \mathrm{MJ}$ of (visible) incident energy on $1 \mathrm{~m}^{2}$ just below the ocean surface. To fix the ideas, the daily insolation within the visible part of the spectrum and at sea level is (ignoring the cloudiness) about $12 \mathrm{MJ} \mathrm{m}^{-2} \mathrm{~d}^{-1}$ in the equatorial belt and ranges from 0 to 13

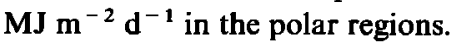

As expected, the local heating rate in the upper layers is much lower in oligotrophic waters than in eutrophic ones, while the converse is true for the deeper layers. It also appears that the various waters experience practically the same heating around a depth of about $3 \mathrm{~m}$, a result which was not easily predictable.

The cumulative effect of this heating process can be com- 


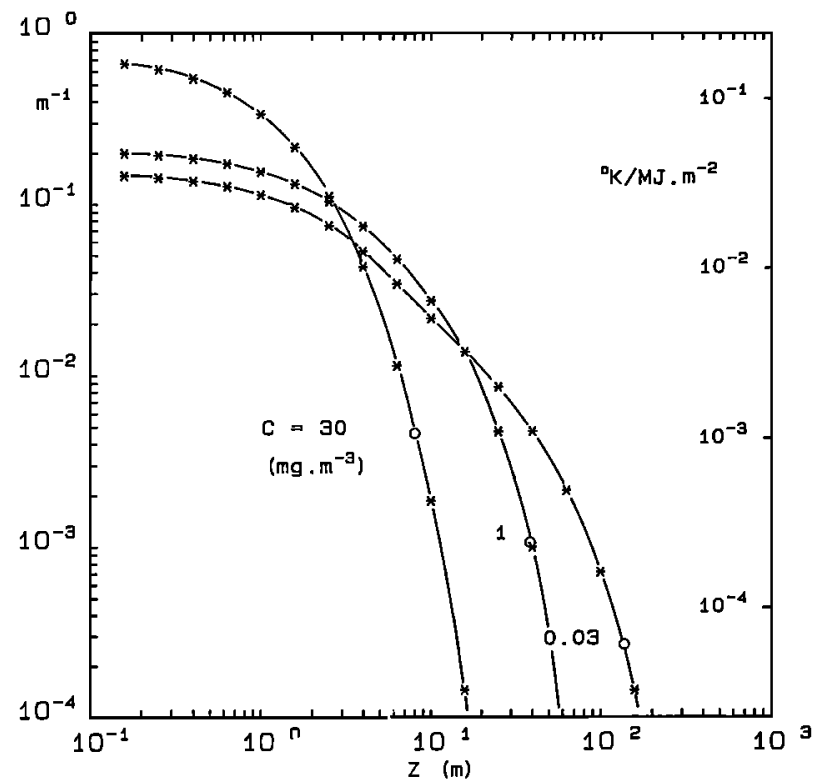

Fig. 16. Visible radiation absorption rates are shown as a function of depth for three selected water bodies characterized by their pigment concentrations at $0.03,1$, and $30 \mathrm{mg} \mathrm{m}^{-3}$. These rates (left-hand ordinate scale) are expressed as the ratios of the locally absorbed energy (per unit of volume) to the incident energy at the surface (per unit of area) and thus are expressed as $\mathrm{m}^{-1}$. The same curves can be seen as heating rates profiles (right-hand ordinate scales) expressed as kelvins per unit of radiant energy $\left(\mathrm{MJ} \mathrm{m}^{-2}\right)$ crossing the air-water interface. The depths where $99 \%$ of the incident energy is absorbed (i.e., at $Z=Z_{e}{ }^{k}$ ) are shown as circles.

puted by using (11) in conjunction with (9) and (10). The fraction of radiant energy which is absorbed above a fixed depth is expressed in (11) as $1-r$ (with $1-r=0.99$ when the depth is that of the euphotic zone). The cumulative curves established in this manner for diverse $C$ values are presented on Figure 17. At $1 \mathrm{~m}$ (a depth where practically all the IR radiation is already absorbed), from $13 \%$ to $50 \%$ of the visible

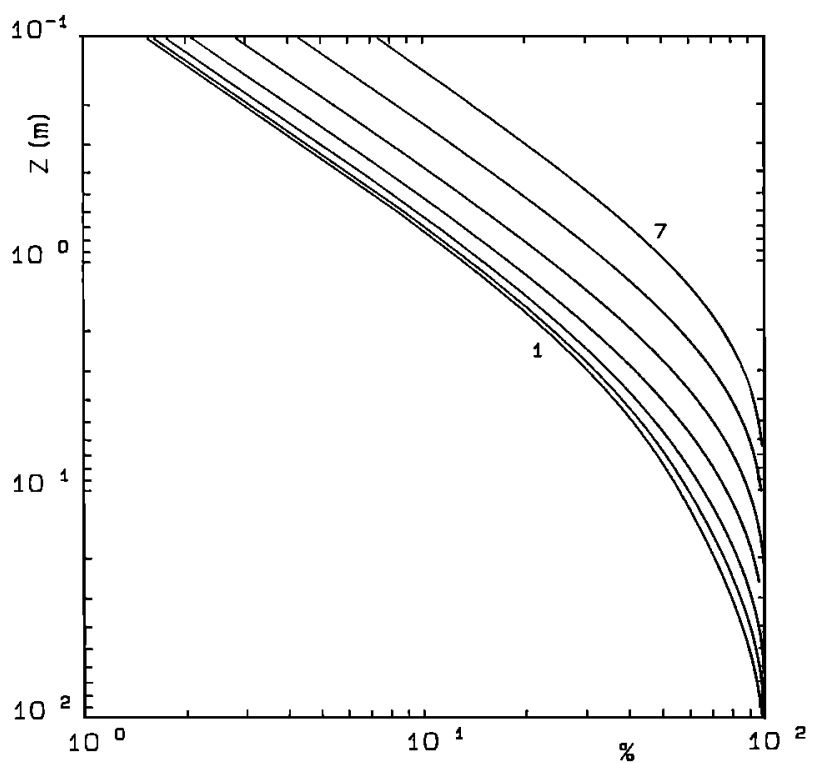

Fig. 17. Ratio (1n percent) of the visible radiant energy absorbed within the layer extending from the surface to the depth $Z$ to the incoming energy having crossed the air-water interface. This ratio is shown as a function of $Z$ for case I waters with varying pigment concentrations, ranging from 0.03 to $30 \mathrm{mg} \mathrm{m}^{-3}$, with the same notation as in Figure 13.

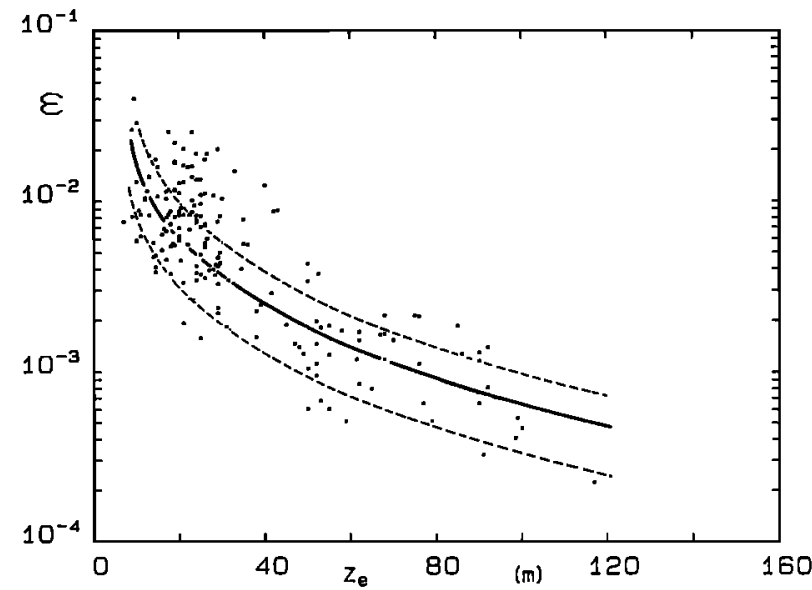

Fig. 18. Ratio $\varepsilon$ (=PSR/PAR) of the daily photosynthetically stored radiation within the euphotic layer to the (daily) photosynthetic available radiation at the surface; this ratio is plotted as a function of the depth of the euphotic layer, and each point corresponds to a primary production station (Table 1). The three curves are drawn according to (24).

radiation is absorbed according to whether the water is oligotrophic or eutrophic $\left(C=0.03\right.$ or $\left.30 \mathrm{mg} \mathrm{m}^{-3}\right)$.

\section{Rate of Radiant Energy Storage Through the Photosynthesis Process}

The daily primary production (or carbon fixation) within the entire euphotic zone, after being converted into its energetic equivalent (on the basis of $39 \mathrm{~kJ}$ per gram of $C$ transferred from $\mathrm{CO}_{2}$ to organic matter), provides the photosynthetically stored radiation (PSR). By forming the ratio of PSR to PAR a dimensionless parameter $\varepsilon$ is obtained which describes the energy storage efficiency of photosynthesizing algae. This number allows meaningful comparisons to be made between various oceanic zones, since the influence of variable insolations upon production is eliminated. These $\varepsilon$ values are plotted as a function of the depth of the euphotic zone (Figure 18). In spite of a relatively scattered distribution of the points a clear pattern is revealed, with the highest $\varepsilon$ values of about $2 \%$ for thin euphotic layers with high chlorophyll content and $\varepsilon$ values 50 or 100 times less in oligotrophic situations. A question immediately arises: To what extent is this pattern fully accounted for by the varying amount of algal biomass present in the euphotic layer?

While the algal biomass integrated through the photic zone

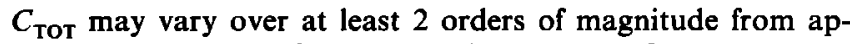

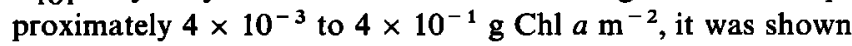
[Morel, 1978], and it has been thereafter confirmed [Platt, 1986] that the efficiency number, once divided by $C_{\mathrm{TOT}}$, produces a kind of biogeochemical "constant." In Morel's study, only the results (30 data) from the SCOR/WG 15 and CINECA 5 cruises (Table 1) were used. The "constant" $\psi$ (notation of Falkowski [1981]) which resulted from this study is

$$
\psi=0.07 \mathrm{~m}^{2}(\mathrm{~g} \mathrm{Chl} a)^{-1}
$$

within $\pm 50 \%$ at $1 \sigma$. Therefrom the energy storage by photosynthesis can be written as

$$
\operatorname{PSR}=0.07( \pm 0.035) \mathrm{PAR} \times C_{\mathrm{TOT}}
$$

or by reversing the joule-to-carbon correspondence and expressing PAR in moles of photons on the basis of $1 \mathrm{~J}=2.5$ 


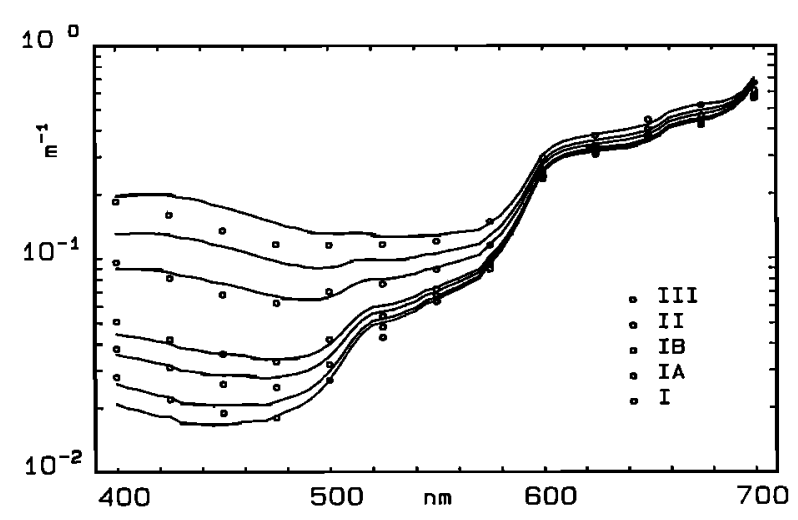

Fig. 19a. The circles show the spectral values of the attenuation coefficient for downwelling irradiance according to Jerlov's optical classification (from bottom to top, types I-III). The curves computed from equation (9) correspond (from bottom to top) to increasing pigment concentrations, namely, $0,0.01,0.05,0.1,0.5,1$, and $2 \mathrm{mg} \mathrm{m}^{-3}$.

$\times 10^{18}$ quanta in the aquatic environment [Morel and Smith, 1974]

$$
\text { mol } C \text { fixed }=0.036( \pm 0.018) \mathrm{mol} \text { photons } \times C_{\text {ToT }}
$$

These relationships express that when normalized to total pigment, the energy (or $\mathrm{CO}_{2}$ ) fixation per unit area of ocean is linearly related to the surface insolation (visible part).

The total pigment content $C_{\text {TOT }}$ has previously been linked to the depth of the euphotic layer $Z_{e}$ through (3), which combined with (22) gives

$$
\varepsilon=\text { PSR } / \text { PAR }=\psi 4.91 Z_{e}^{-1.34}=0.344( \pm 0.17) Z_{e}^{-1.34}
$$

The corresponding $\varepsilon$ curves, as a function of $Z_{e}$, are drawn on Figure 18. Most of the experimental points (207) fall within the band delimited by the extreme $\psi$ values. The large amount of additional data (177), along with those data (30) previously used to obtain the above $\varepsilon$ value, bring out the ubiquity of the "natural law" transcribed by (23) and subsequently by (24). The estimate of the primary production from satellite surveys of ocean color and insolation certainly can benefit from the existence of such a law.

Underlying the geochemical constant $\psi$ are two distinct phenomena: the efficiency of algae (or of the living carbon pool) in capturing radiant energy and the yield in converting this energy into an increase of organic carbon. This can be made clear by considering that the quantity $\psi$ has the dimension of, and can be seen as, a cross section for photosynthesis normalized to chlorophyll. Its dimensional nature is similar to $a^{*}$ (absorption cross section of algae normalized to chlorophyll), which can be obtained by averaging $a^{*}(\lambda)$ (Figure 10c) over the appropriate spectral domain. The $\psi$-to- $a^{*}$ ratio is nothing else than the efficiency factor in converting absorbed energy into chemical energy, that is, a depth-averaged quantum yield for growth $\phi_{\mu}$. The threefold possible change in $\psi$ implies that the product $a^{*} \phi_{\mu}$ is restricted to vary within the same range in the natural environment and independently from the biomass present. Additional knowledge about the stratification of the algal population, its physiological or adaptative state, and the nutrient availability is required to allow a more accurate estimate of $a^{*} \phi_{\mu}$ to be made and therefore the primary production of a given biomass to be predicted within a factor better than 3 .

\section{Comparison With Other Optical Classifications and Models}

The basis of the classification set up by Jerlov [1951] is that the downwelling irradiance attenuation coefficient $K_{d}(\lambda)$ for any wavelength can be expressed as a linear function of $K_{d}$ at a reference wavelength ( $\lambda=475 \mathrm{~nm}$ in the study by Jerlov). The oceanic types I, IA, IB, II, and III are thus defined through their $K_{d}(475)$ values, with the consequence that all the $K_{d}(\lambda)$ values are fixed for a given type [Jerlov, 1976, Table 27]. By comparing these spectra to those resulting from equation (9), used with the coefficients in Table 2, a specific pigment concentration can be assigned to each of Jerlov's water types. Because there is not a perfect agreement between Jerlov's $K_{d}$ spectra and those generated through (9), only approximate $C$ values can be determined (see also Figure 19a).

$$
\underset{\text { I }}{0.01} \underset{\text { IA }}{0.05} \underset{\text { IB }}{0.1} \underset{\text { II }}{0.5} \underset{\text { III }}{0.5-2} \mathrm{mg} \mathrm{m}^{-3}
$$

The discrepancies between the two families of spectra are the following: (1) for water type I the attenuation values are slightly less than those adopted for $K_{w}$ beyond $500 \mathrm{~nm}$, (2) the increase in water absorption, occurring between 500 and 520 $\mathrm{nm}$, is not reproduced in Jerlov's spectra which exhibit regular slopes between 500 and $580 \mathrm{~nm}$, and (3) in the blue to violet part of the spectrum (from 475 to $400 \mathrm{~nm}$ ) the slopes of the type II and III waters are steeper than those of the $K(\lambda)$ spectra corresponding to pigment concentrations ranging from 0.5 to $2 \mathrm{mg} \mathrm{m}^{-3}$.

The above discrepancies reflect the improvements which have resulted from a better knowledge of the optical constant of optically pure water [Smith and Baker, 1981] as well as from the considerable amount of spectral data acquired at sea since the pioneer work effected by Jerlov.

Note that Jerlov's coastal types 1-9, representative, in effect, of yellow substance dominated waters (see discussion by Morel [1982]), are outside the present modeling, valid only for case I waters. Charts of Jerlov's water types in the world ocean have been prepared [Jerlov, 1976] and improved [Simonot and Le Treut, 1986] for the purpose of climatological modeling of solar heating. Future satellite data giving access to the pigment concentration of the upper layer will allow prediction of Figures 15 and 16 to be systematically used in a thermodynamic modeling of the sea surface temperature and mixed layer depth.

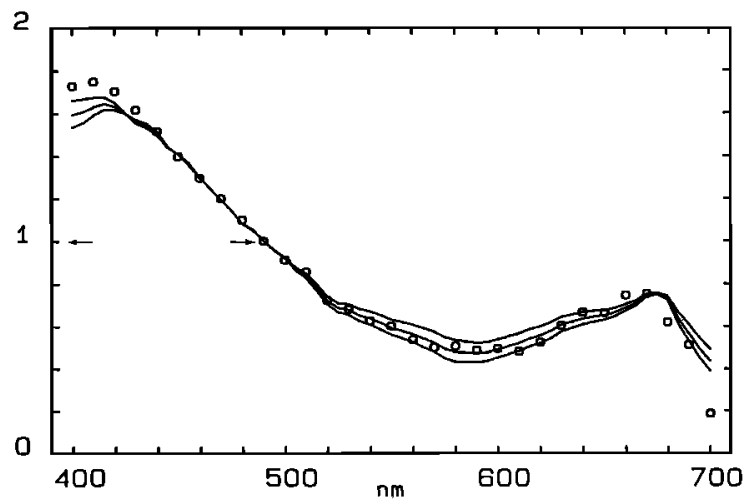

Fig. 19b. The circles correspond to the slopes $M(\lambda)$ obtained by Austin and Petzold [1986] (see text), whereas the curves are obtained by using equation (9) with three values for the pigment concentration (see text). 


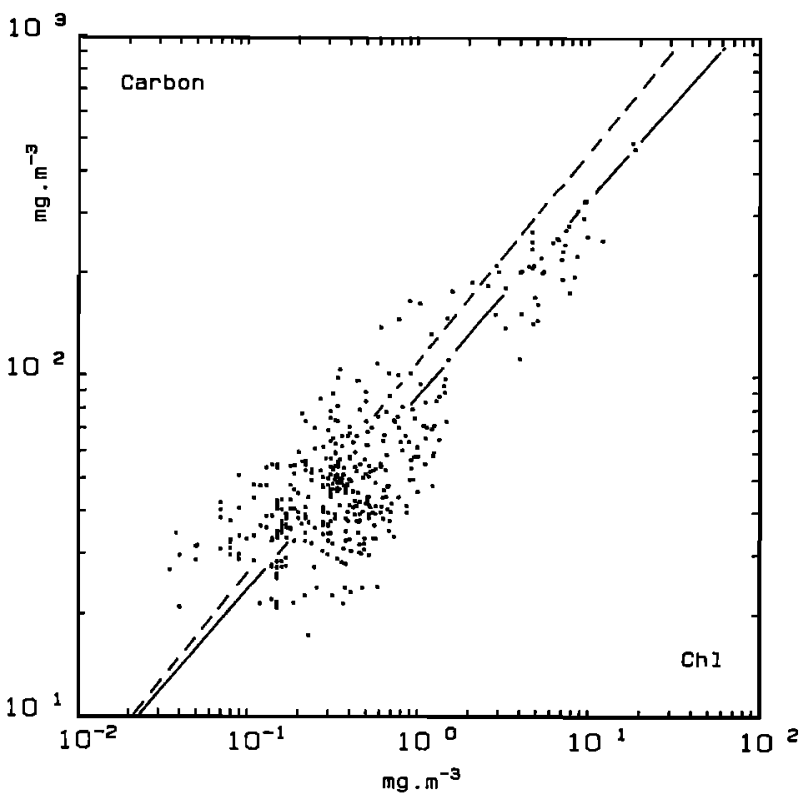

Fig. 20. Particulate organic carbon concentration $\langle C\rangle$, as a function of chlorophyll concentration $\langle\mathrm{Chl}\rangle$ in the same sample (see also Table 1). The solid and dashed lines in this log-log plot correspond to expressions (25) and (28), respectively.

The analysis carried out by Austin and Petzold [1986] rests on a basic idea similar to Jerlov's, that is, the existence of a linear relationship between any $K_{d}(\lambda)$ and $K_{d}(490)$ at least up to some maximum value of $K_{d}(490)-0.16 \mathrm{~m}^{-1}$ in their study. Such an assumption is contradictory to the existence in (9) of an exponent allowed to vary with $\lambda$. However, in a restricted range of $K_{d}(490)$ values (or equivalently of $C$ values) the nonlinear behavior is reduced, since the $e(\lambda)$ values are not very different. By fitting linear equations of the form

$$
K(\lambda)=M(\lambda)\left[K(490)-K_{w}(490)\right]+K_{w}(\lambda)
$$

Austin and Petzold calculated the "slopes" $M(\lambda)$ plotted on Figure $19 b . M(\lambda)$ can also be computed by using (9), with the difference that the $M(\hat{\lambda})$ values are no longer unique but varying with varying pigment concentration. The curves for $C=0.3,1$, and $3 \mathrm{mg} \mathrm{m}^{-3}$ are also shown on Figure $19 b$ (these $C$ values are consistent with the $K(490)$ envisaged by Austin and Petzold). The agreement is remarkable and increases the confidence in the modeled case I waters properties since this comparison demonstrates the perfect compatibility of two sources of data.

The bio-optical model of natural waters established by Baker and Smith [1982] is in essence similar to the model presented here; in addition, it can include the dissolved organic material (DOM) component. When DOM is negligible, the $K(\lambda)$ values depend only on the pigment concentration according to an analytical expression (Baker and Smith's (6)) which involves three parameters varying with $\lambda$. This relationship for $\lambda=450 \mathrm{~nm}$ is graphically presented in Figure $7 a$. A numerical comparison of the products of their model with those of (9), used with the values in Table 2, reveals a marked divergence in the 400- to $550-\mathrm{nm}$ domain when $C$ is about 1 or $2 \mathrm{mg} \mathrm{m}^{-3}$. The "bump" which occurs for these concentrations (Figure $7 a$ ) produces higher $K(\lambda)$ when using the Baker-Smith model. The data used in the present study do not support the reality of enhanced $K$ values in this range of concentration or the need for curvatures to get a better fit. It is believed that the simple power law (9) is more accurate in reproducing the field data.

\section{Discussion and Conclusion}

In case I waters the optical properties are solely governed by phytoplankton and their immediate derivatives. They are not, however, linearly correlated to the amount of algae, as depicted by the chlorophyll $a$ ( + pheophytin $a$ ) concentration. This nonlinear biological effect on several optical properties of the ocean has been analyzed and its consequences derived. Before discussion the main features can be summarized as follows: (1) the spectral attenuation coefficients $K(\lambda)$ increase more slowly than does the pigment concentration $C$ (power law with exponents of about 0.7 ), (2) the scattering coefficient $b$ also increases more slowly than does $C$ (exponent equal to $0.62)$, (3) $k_{c}(\lambda)$, the spectral values of the Chl-specific attenuation coeflicient of the algal material (living and detrital), are not constant because they all decrease with increasing pigment concentration, and (4) the shape of the $k_{c}(\lambda)$ spectrum changes with $C$, resembling that of absorption by detritic material at low $C$ or by living algae, grown in culture, at high $C$.

It has not been attempted, however, to examine the origin of these nonlinear behaviors. The idea was put forward that a regular change in the relative proportions of the subcomponents inside the biogenic compartment could explain the observed nonlinearity (the subcomponents being the living algal cells, the particulate, and the dissolved detrital materials). This explanation must be supported by other kinds of observations.

\section{Pigment, Organic Carbon, and Seston \\ Relationships in Case I Waters}

Along with the pigment determination the particulate organic carbon (POC) has also been measured on the same samples taken in the euphotic layer. These data (case II excluded) are plotted on Figure 20. Even if the "cloud" cannot lead to a high correlation coefficient between the logtransformed data $\left(N=409, r^{2}=0.68\right)$, it remains that an unambiguous trend exists. The regression analysis lead to the following, slightly rounded, relationship

$$
\langle C\rangle=90\langle\mathrm{Chl}\rangle^{0.57}
$$

where $\langle C\rangle$ symbolizes the POC concentration (in $\mathrm{mg} \mathrm{m}^{-3}$ ) and $\langle\mathrm{Chl}\rangle$ (also in $\mathrm{mg} \mathrm{m}^{-3}$ ) replaces the previous notation $C$ (to prevent confusing it with carbon). This relationship acknowledges that when $\langle\mathrm{Chl} a\rangle$ spans almost 3 orders of magnitude, $\langle C\rangle$ experiences a change restricted to only 1.5 orders of magnitude. The data, published by Huntsman and Barber [1977], for offshore stations in the Mauritanian upwelling zone, corroborate the present results. A similar relationship $\langle C\rangle=152\langle\mathrm{Chl}\rangle^{0.58}$ can be deduced from the data and regression analysis carried out by Malone [1982].

Scattering measurements also allow another, independent approach to be made. Over 2 orders of magnitude there exists a linear relationship between the scattering coefficient (at 550 $\mathrm{nm}) b$ and the total seston concentration (dried material) denoted $\langle S\rangle$ (expressed as $\mathrm{g} \mathrm{m}^{-3}$ ). This relation [see Gordon and Morel, 1983, Figure 6] is simply written

$$
b /\langle S\rangle=1 \mathrm{~m}^{2} / \mathrm{g} \quad \text { (seston) }
$$

Between $b$ and $\langle\mathrm{Chl} a\rangle$ another statistical relationship has been previously mentioned in (18), which is recalled:

$$
b=0.30\langle\mathrm{Chl}\rangle^{062}
$$


TABLE 4. Values Used for Computation of $K(\lambda)$ as a Function of (Chl)

\begin{tabular}{llll}
\hline & \multicolumn{3}{c}{ Wavelength, nm } \\
\cline { 2 - 4 } & 440 & \multicolumn{1}{c}{565} & 690 \\
\hline$a_{w}, \mathrm{~m}^{-1}$ & 0.0145 & 0.0754 & 0.500 \\
$b_{w}, \mathrm{~m}^{-1}$ & 0.0050 & 0.00173 & 0.0007 \\
$a^{*}, \mathrm{~m}^{2} \mathrm{mg}^{-1}$ & 0.044 & 0.007 & 0.007 \\
$B$ & 0.375 & 0.290 & 0.239 \\
\hline
\end{tabular}

By substitution, it becomes

$$
\langle S\rangle=0.30 \times 10^{3}\langle\mathrm{Chl}\rangle^{0.62}
$$

where $\langle S\rangle$, like $\langle\mathrm{Chl}\rangle$, is expressed as milligrams per cubic meter. For the upper layers of the ocean it was shown [Copin, 1980] that the carbon-to-seston ratio takes its higher value, about 1-2.7 (mass per mass). Accordingly, (27) can be rewritten as

$$
\langle C\rangle=110\langle\mathrm{Chl}\rangle^{0.62}
$$

which, in an indirect way, nicely supports the above statistical product expressed by (25). In addition, the practically insignificant difference between the exponents appearing in (25) and (18) strongly suggests that the scattering coefficient is linearly related to the particulate organic carbon concentration.

To the extent that the optical properties (namely, $K(\lambda), k_{c}(\lambda)$, and $b$ ) depend not only on the pigmented particles, depicted by $\langle\mathrm{Chl}\rangle$, but also on the total seston, depicted by $\langle S\rangle$, the nonlinear biological effect becomes understandable, as being a consequence of the nonlinearity inside the biogenic compartment as expressed by (25). Another geochemical consequence of this nonlinearity is the progressive change of $\theta$, which is the carbon-to-chlorophyll ratio in the natural environment. For a pigment concentration going from 0.02 to 1 and finally to $20 \mathrm{mg} \mathrm{m}^{-3}$ the corresponding $\theta$ values are about 1000,100 , and 25 . It is known that living cells may experience considerable changes in $\theta$, as a physiological response to light and nutrient limitations (see, e.g., Falkowski [1980] and Kiefer and Mitchell, 1983]). They are, however, not as wide as the above values, and overall it is doubtful that they should be so regularly well ordered with respect to the trophic state of the water. The increasing relative role played by detrital particles (perhaps also by nonpigmented bacterial) is presumably at the origin of the increasing carbon-topigment ratio when the algal biomass decreases. Anyway, because of either the diminishing cellular pigment content or the relatively more abundant detritus the result is the same from an optical viewpoint; more suspended particles per unit of pigment are present at low biomass. More particles entail more scattering per unit of pigment [see Morel, 1987] with a consequence on the $K$ coeflicients which remains to be assessed.

\section{Absorption and Scattering Roles in Forming $K_{d}$}

The attenuation coefficient for downwelling irradiance $K_{d}$, which is not an inherent optical property, is nevertheless dependent on two inherent properties $a$ and $b$, the absorption and scattering coefficients (and on the angular structure of the light fields). At the midpoint of the euphotic zone, for a wide range of $b / a$ values and high sun conditions, Kirk [1981] has obtained through Monte Carlo calculations the following expression:

$$
K_{d} \simeq\left(a^{2}+0.256 a b\right)^{1 / 2}
$$

which can be used as a sufficient approximation in the problem addressed.

By using (18) the scattering coefficient of a water body can be expressed as a function of its pigment concentration according to

$$
b(\lambda)=b_{w}(\lambda)+B(\lambda)\langle\mathrm{Chl}\rangle^{0.62}
$$

with $B=0.30$ when $\lambda=550 \mathrm{~nm}$ and $B(\lambda)=0.3(\lambda / 550)^{-1}$ for other wavelengths. By adopting for the present trial the chlorophyll-specific absorption values for algae grown in culture (the "averaged" values), shown in Figure $10 c$, the absorption coefficient can be expressed as

$$
a(\lambda)=a_{w}(\lambda)+a^{*}(\lambda)\langle\mathrm{Chl}\rangle+a_{\text {det }}
$$

where $a_{\mathrm{det}}$ is that part of absorption due to the presence of detritus and bacteria. These substances, while less pigmented than living cells, may have a noticeable influence, particularly in the short-wavelength domain. This term could be modeled as a function of the pigment concentration (1) if a relationship between the dissolved organic substance (yellow substance) and the algal concentration in case $I$ waters exists and is available, and (2) if a specific absorption coefficient (preferably a carbon-specific coefficient) for the detrital particulate is known. The present knowledge is insufficient to assess quantitatively $a_{\mathrm{dec}}$, and this term will be simply ignored in the following computation. Its absence, however, has to be kept in mind when discussing the results.

By taking as examples the wavelengths 440 and $565 \mathrm{~nm}$, which are those of the approximate maximum and minimum algal absorption, and, for comparison, $690 \mathrm{~nm}$ as typical of the red end of the spectrum, $K(\lambda)$ can be computed as a function of $\langle\mathrm{Chl}\rangle$. The values in Table 4 are used for this computation.

The computed $K(\lambda)$ values are plotted versus the pigment concentration on Figure 21, along with the curves which are derived from the regression analysis (with $K_{w}(\lambda), \chi(\lambda)$, and $e(\lambda)$

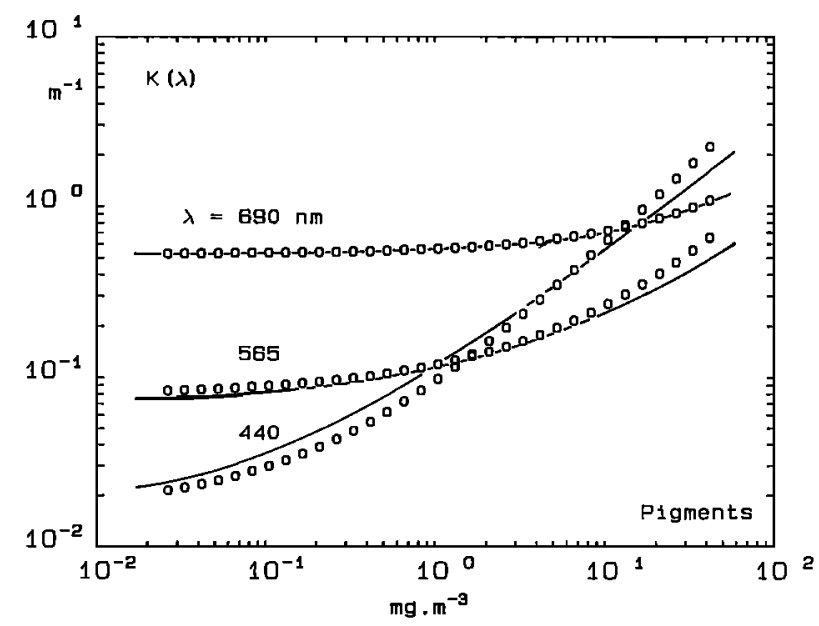

Fig. 21. Spectral values (for 440,565 , and $690 \mathrm{~nm}$ ) of the attenuation coefficient for downwelling irradiance as a function of the mean pigment concentration within the considered layer. The curves, similar to those in Figures $7 b-7 d$, are derived from the regression analysis. The points represent the values obtained through equation (29) by using the absorption and scattering coefficients which are made dependent on the pigment content (see text). 
taken from Table 2). A satisfactory agreement between the two kinds of results is obtained. In spite of its approximate character the model is able to reproduce the nonlinear $K(\lambda)$ pattern and to explain this pattern as the result of the combined influences of scattering and absorption (both phenomena which are themselves strongly wavelength-dependent).

In the range of high pigment concentrations the computed $K$ values for 440 and $565 \mathrm{~nm}$ tend to exceed those resulting from the regression analysis. This excess presumably results from the Chl-specific absorption values adopted above, perhaps too high for algae living in a natural eutrophic environment. On the basis of the scattering properties there are strong arguments in favor of the predominance, in eutrophic waters, of big-sized algal cells with high intracellular concentration [Morel, 1987]. The "discreteness" or "package" effect [Kirk, 1975; Morel and Bricaud, 1981] is therefore enhanced and reduces the Chl-specific absorption capabilities of such algae. A sensitivity test effected on equation (29) shows that when reducing $a^{*}(440)$ and $a^{*}(565)$ by $30 \%$, a reasonable assumption concerning the discreteness effect, the two kinds of curves become practically confounded at high pigment concentration. At low pigment concentration the computed $K(440)$ values are below the actual ones, very likely because absorption by the detrital and nonalgal materials has been ignored.

In conclusion, the nonlinear biological effect on the optical properties is reasonably well understood. At the level of the biological material itself there exists a rather regular evolution from the oligotrophic situation, where detrital (or at least nonpigmented) organic carbon predominates over the living pigmented carbon, to the eutrophic situation, where the converse is true. These changes inside the biological compartment concern the relative proportions and not the absolute values of the biological material concentration, which obviously decreases from eutrophic to oligotrophic waters (by 3 orders of magnitude with respect to chlorophyll and by 1.5 orders of magnitude with respect to particulate carbon). At the level of the optical properties resulting from the presence of the biological material, weakly pigmented or unpigmented particles contribute to increasing the attenuation coefficients essentially through their scattering properties, whereas pigmented cells act simultaneously as absorbers and scatterers. These optical contributions, when weighted by the changing proportions as recalled above, account well for observation. In oligotrophic oceanic waters, in addition to the "blue absorbing" particulates, the endogeneous yellow substance, albeit hardly measurable, is not optically negligible [Bricaud et al., 1981] and could be partly at the origin of the enhanced Chl-specific attenuation coefficient (the $k_{c}(\lambda)$ values) in the blue part of the spectrum. This conclusion is also supported by the results obtained by Prieur and Sathyendranath [1981], who demonstrated that yellow substance absorption is never absent and that partial absorption by phytoplankton is relatively enhanced at low pigment concentration. In eutrophic waters, with a lower detrital-to-living materials ratio, the optical properties tend to ressemble that of dilute culture of algae, exhibiting low chlorophyll-specific scattering and absorption coefficients, as a consequence of a marked package effect.

Acknowledgments. For many years, many people were involved in the acquisition of the various field data used in the present study; their names appear in the cruise reports. They are duly and collectively acknowledged. The author would like to express his particular appreciation to $A$. Bricaud and $\mathbf{L}$. Prieur for their constructive assistance, to D. Tailliez for his continuous help in programing, and to A. Herbland, who made available unpublished carbon-chlorophyll data. This work, mainly supported by the Centre National de la Recherche Scientifique (UA 353 and GRECO P4), is a contribution to the research encouraged by the former International Association for Physical Sciences of The Oceans Working Group on "Optical Oceanography" (now Subcommission on "Oceanography from Space").

\section{REFERENCES}

Atlas, D., and T. T. Bannister, Dependence of mean spectral extinction coefficient of phytoplankton on depth, water color, and species, Limnol. Oceanogr., 25, 157-159, 1980.

Austin, R. W., The remote sensing of spectral radiance from below the ocean surface, in Optical Aspects of Oceanography, edited by N. G. Jerlov and E. S. Nielsen, pp. 317-344, Academic, San Diego, Calif., 1974.

Austin, R. W., and T. J. Petzold, Spectral dependence of the diffuse attenuation coeflicient of light in ocean waters, Opt. Eng., 25, 471$479,1986$.

Baker, K. S., and R. C. Smith, Bio-optical classification and model of natural waters II, Limnol. Oceanogr., 27, 500-509, 1982.

Barber, R. T., and S. A. Huntsman (Eds.), Coastal Upwelling Ecosystems Analysis, Joint 1, Data Rep., 14, 165 pp., Duke Univ. Mar. Lab., Beaufort, N. C., 1975.

Barber, R. T., S. A. Huntsman, J. E. Kogelschatz, W. O. Smith, B. H. Jones, and J. C. Paul, (Eds.), Coastal Upwelling Ecosystems Analysis, Joint 2, Data Rep., 49, 476 pp., Duke Univ. Mar. Lab., Beaufort, N. C., 1978.

Bricaud, A., and A. Morel, Light attenuation and scattering by phytoplanktonic cells. A theoretical modeling, Appl. Opt., 25, 571-580, 1986.

Bricaud, A., and A. Morel, Atmospheric corrections and interpretation of marine radiances in CZCS imagery: Use of a reflectance model, Oceanol. Acta, 7, 33-50, 1987.

Bricaud, A., A. Morel, and L. Prieur, Absorption by dissolved organic matter of the sea (yellow substance) in the U.V. and visible domains, Limnol. Oceanogr., 26, 43-53, 1981.

Bricaud, A., A. Morel, and L. Prieur, Optical efficiency factors of some phytoplankters, Limnol. Oceanogr., 28, 816-832, 1983.

Bricaud, A., A. L. Bedhomme, and A. Morel, Optical properties of diverse phytoplanktonic species: Experimental results and theoretical interpretation, J. Plankton Res., in press, 1988.

Copin, G., Matières en suspension dans les eaux de mer: Répartition, composition chimique, origine et évolution, thèse d'Etat, $173 \mathrm{pp}$., Univ. Pierre et Marie Curie, Paris VI, 1980.

Dubinsky, Z., and T. Berman, Seasonal changes in the spectral composition of downwelling irradiance in Lake Kinneret (Israël), Limnol. Oceanogr., 24, 652-663, 1979.

Falkowski, P. G., Light-shade adaptation in marıne phytoplankton, Brookhaven Symp. Biol., 31, 99-119, 1980.

Falkowski, P. G., Light-shade adaptation and assimilation numbers, J. Plankton Res., 3, 203-216, 1981.

Gordon, H. R., and A. Morel, Remote assessment of ocean color for interpretation of satellite visible imagery, A review, in Lecture Notes on Coastal and Estuarine Studies, edited by R. T. Barber, C. N. K. Mooers, M. J. Bowman, and B. Zeitzchel, 114 pp., SpringerVerlag, New York, 1983.

Gordon, H. R., O. B. Brown, and M. M. Jacobs, Computed relationships between the inherent and apparent optical properties of a flat homogeneous ocean, Appl. Opt., 14, 417-427, 1975.

Groupe MEDIPROD, Résultats des campagnes à la mer no. 7 , CINECA 2 Cruise report, 138 pp., Cent. Natl. pour l'Exploit. des Oceans, Brest, France, 1971.

Groupe MEDIPROD, Résultats des campagnes à la mer no. 10, CINECA 5 Cruise report, Cent. Natl. pour L'Exploit. des Oceans, Brest, France, 1976.

Groupe MEDIPROD, Résuitats des campagnes à la mer no. 13, GUIDOM Cruise report, Cent. Natl. pour l'Exploit. des Oceans, Brest, France, 1977.

Groupe MEDIPROD, Résultats des campagnes à la mer no. 16, ANTIPROD Cruise report, 151 pp., Cent. Natl. pour l'Exploit. des Oceans, Brest, France, 1978.

Groupe MEDIPROD, Résultats des campagnes à la mer no. 19, CIPREA Cruise report, 250 pp., Cent. Natl. pour l'Exploit. des Oceans, Brest, France, 1981.

Groupe MEDIPROD, Résultats des campagnes à la mer no. 25, RCA Cruse report, 115 pp., Cent. Natl. pour l'Exploit. des Oceans, Brest, France, 1983. 
Groupe MEDIPROD, Résultats des campagnes à la mer, PACIPROD Cruise report, Centl. Natl. pour l'Exploit. des Oceans, Brest, France, in press, 1988.

Huntsman, S. A., and R. T. Barber, Primary production off northwest Africa: The relationship to wind and nutrient conditions, Deep Sea Res., 24, 25-33, 1977.

Jerlov, N. G., Optical studies of ocean water, Rep. Swed. Deep Sea Exped., 1947 1948, 3, 1-19, 1951.

Jerlov, N. G., Marine Optics, Elsevier Oceanogr. Ser., vol. 14, 231 pp., Elsevier, Amsterdam, 1976.

Jitts, H. R., A. Morel, and Y. Saijo, The relation of oceanic primary production to available photosynthetic irradiance, Aust. J. Mar. Freshwater Res., 27, 441-454, 1976.

Kiefer, D. A., and B. G. Mitchell, A simple steady state description of phytoplankton growth based on absorption cross section and quantum efliciency, Limnol. Oceanogr., 28, 770-775, 1983.

Kiefer, D. A., and J. B. Soohoo, Spectral absorption by marine particles of coastal waters of Baja California, Limnol. Oceanogr., 27, 492-499, 1982.

Kirk, J. T. O., A theoretical analysis of the contribution of algal cells to the attenuation of light within natural waters, I, General treatment of suspensions of living cells, New Phytol., 75, 11-20, 1975.

Kirk, J. T. O., A Monte-Carlo study of the nature of the underwater light field in, and relationships between optical properties of, turbid yellow waters, Aust. J. Mar. Freshwater Res., 32, 517-532, 1981.

Kirk, J. T. O., Light and Photosynthesis in Aquatic Ecosystems, 401 pp., Cambridge University Press, New York, 1983.

Kishino, M., N. Okami, M. Takahashi, and S. Ichimura, Light utilization efficiency and quantum yield of phytoplankton in a thermally stratified sea, Limnol. Oceanogr., 3I, 557-566, 1986.

Lorenzen, C. J., Surface chlorophyll as an index of the depth, chlorophyll content and primary productivity of the euphotic layer, Limnol. Oceanogr., 15, 479-480, 1970.

Lorenzen, C. J., Extinction of light in the ocean by phytoplankton, $J$. Cons. Cons. Int. Explor. Mer, 34, 262-267, 1972.

Malone, T. C., Phytoplankton photosynthesis and carbon-specific growth: Light saturated rates in a nutrient rich environment, Limnol. Oceanogr., 27, 226-235, 1982.

Minas, H. J., Résultats de la campagne Mediprod 1, Cah. Océanogr., 23, 93-144, 1971.

Morel, A., Diffusion de la lumière par les eaux de mer, résultats expérimentaux et approche theorique, in Optics of the Sea, AGARD Lect. Ser., vol. 61, pp. 3.1.01-3.1.76, Advisory Group for Aeronautical Research and Development, NATO, Brussels, 1973.

Morel, A., Optical properties of pure water and pure sea water, in Optical Aspects of Oceanography, edited by N. G. Jerlov and E. Steemann Nielsen, pp. 1-24, Academic, San Diego, Calif., 1974.

Morel, A., Avallable usable, and stored radiant energy in relation to marıne photosynthesis, Deep Sea Res., 25, 673-688, 1978.

Morel, A., In-water and remote measurement of ocean color, Boundary Layer Meteorol., 18, 177-201, 1980.

Morel, A., Optıcal properties and radiant energy in the waters of the Guinea Dome and the Mauritanian upwelling area in relation to primary production, Rapp. P. V. Reun. Cons. Int. Explor. Mer, 180 , 94-107, 1982.

Morel, A., Chlorophyll-specific scaltering coefficient of phytoplankton, a simplified theoretical approach, Deep Sea Res., 34, 1093$1105,1987$.
Morel, A., and A. Bricaud, Theoretical results concerning light absorption in a discrete medium and application to specific absorption of phytoplankton, Deep Sea Res., Part A, 28, 1375-1393, 1981.

Morel, A., and L. Prieur, Analysis of variations in ocean color, Limnol. Oceanogr., 22, 709-722, 1977.

Morel, A., and R. C. Smith, Relation between total quanta and total energy for aquatic photosynthesis, Limnol. Oceanogr., 19, 591-600, 1974

Platt, T., Primary production of the ocean water column as a function of surface light intensity: Algorithms for remote sensing, Deep Sea Res., 33, 149-163, 1986.

Preisendorfer, R. W., Application of radiative transfer theory to light measurements in the sea, Monogr. $J 0$, pp. 11-30, Intl. Union Geod. Geophys., Paris, 1961.

Preisendorfer, R. W., Hydrologic optics, vol. 1, Introduction, Pac. Mar. Environ. Lab., Environ Res. Lab., Natl. Oceanic and Atmos. Admin., Seattle, Wash., 1976.

Prieur, L., Transfert radiatif dans les eaux de mer: application à la détermination des paramétres optiques caractérisant leur teneur en substances dissoutes et particulaires thèse d'Etat, $243 \mathrm{pp}$., Univ. Pierre et Marie Curie, Paris, 1976.

Prieur, L., and S. Sathyendranath, An optical classification of coastal and oceanic waters based on the specific spectral absorption curves of phytoplankton pigments, dissolved organic matter and other particulate materials, Limnol. Oceanogr., 26, 671-689, 1981.

Riley, G. A., Oceanography of Long Island Sound, 1952-54, II, Physical Oceanography, Bull. Bingham Oceanogr. Collect., 15, 15-46, 1956.

Scientific Committee on Oceanic Research (SCOR), Working group 15 data report on the SCOR Discoverer expedition, SIO Ref. 73-16, vol. 2, edited by J. E. Tyler Scripps Inst. of Ocean., La Jolla, Calif., 1973.

Simonot, J. Y., and H. Le Treut, A climatological field of mean optical properties of the world ocean, J. Geophys. Res., 91(C5), 66426646, 1986.

Smith, R. C., and K. S. Baker, The bio-optical state of ocean waters and remote sensing, Limnol. Oceanogr., 23, 247-259, 1978.

Smith, R. C., and K. S. Baker, Optical properties of the clearest natural waters, Appl. Opt., 20, 177-184, 1981.

Tyler, J. E. (Ed.), Report on the second meeting of the Joint Group of experts on photosynthetic radiant energy, UNESCO Tech. Pap. Mar. Sci., 2, 1-11, 1966

Tyler, J. E., The in situ quantum efficiency of natural phytoplankton populations, Limnol. Oceanogr., 20, 976-980, 1975.

Weidemann, A. D., and T. T. Bannister, Absorption and scattering coefficients in Irondequoit Bay, Limnol. Oceanogr., 31, 576-583, 1986.

Yentsch, C. S., Measurements of visible light absorption by particulate matter in the ocean, Limnol. Oceanogr., 7, 207-217, 1962.

A. Morel, Laboratoire de Physique et Chimie Marines, Université Pierre et Marie Curie, (CNRS, UA 353) BP 8, F 06230 VillefrancheSur-Mer, France.
(Received February 16, 1988; accepted April 20, 1988.) 